Article

\title{
Exploring the Spatial Pattern of Urban Block Development Based on POI Analysis: A Case Study in Wuhan, China
}

\author{
Hailing $\mathrm{Xu}$, Jianghong $\mathrm{Zhu}$ * and Zhanqi Wang \\ School of Public Administration, China University of Geosciences, Wuhan 430074, China; \\ xuhailing1995@cug.edu.cn (H.X.); zhqwang@cug.edu.cn (Z.W.) \\ * Correspondence: tdx_cug@cug.edu.cn; Tel.: +86-1339-715-7676
}

Received: 3 November 2019; Accepted: 4 December 2019; Published: 6 December 2019

check for updates

\begin{abstract}
As a kind of geospatial big data, point of interest (POI) with useful information has become a hot research topic. Compared with traditional methods, big data has great potential in developing a more accurate method for identifying the urban spatial pattern. This paper uses diversity index and kernel density analysis of POI data on several types of urban infrastructure to investigate the identification of urban block development stages in Wuhan, and divides them into the primary, growth, and mature stage. Its accuracy is verified by exploring urban micro-centers. Results show that: (1) the spatial pattern of urban blocks in Wuhan presents the distribution of "mature blocks concentrated like a core, growth blocks distributed like two wings, and primary blocks with wide range distributed surround"; (2) areas with more connected construction land and streets with better socio-economic status tend to have a higher level of maturity, vice versa; (3) balancing the number of micro-centers at different stages is beneficial to promote the flattened urban development of Wuhan in the future. The research proves that this method is feasible, and it is also applicable to the study of urban spatial pattern in other cities.
\end{abstract}

Keywords: POI data; diversity index; kernel density analysis; spatial pattern of urban block development; Wuhan city

\section{Introduction}

The point of interest (POI) of urban facilities is one of the map objects that attract most attention from professional urban planners and ordinary people in the field of digital city. It can describe all kinds of engineering and social service facilities in urban space and contains abundant cultural, economic, and natural information [1]. Due to the strong functional link between different types of facilities, the POIs often appear as a cluster in geospatial spaces, i.e., hotspots, such as the spatial hotspots formed by the clustering of financial facilities, information consulting facilities, and retail facilities in the central business district of the city, as well as the clustering of cultural facilities like landmark buildings and museums in the touristic area [2]. Integrated POI hotspot information together with thematic information like road and human activities can provide rich quantitative data and decision support for urban tourism recommendation, urban planning, commercial site selection, infrastructure planning, and other fields [3-5]. However, the traditional definition of POI hotspots is vague and subjective. How to define hotspots and their spatial locations has always been a problem in the disciplines of GIS and urban planning [1].

At present, studies on the spatial pattern of urban block development in China are mainly based on experience and qualitative analysis, which could be subjective. Due to the lack of quantitative calculation and analysis, how to judge the development stage and spatial pattern of the block accurately 
has become a problem. Some scholars have applied big data to the analysis of urban spatial structure and achieved great results. The most widely used urban data include smart card data used in urban rail transit, mobile phone signaling data, network review data, thermal map data, Weibo sign-in data, and night lights data [6]. Wang et al. employed POI and nighttime light data to map urban road safety at the micro-level in Shanghai [7]; Feng et al. analyzed population aggregation spatiotemporal characteristics in a small city based on the data of Baidu heat maps [8]; Yue et al. conducted a measurement of urban vitality by using multi-source data [9]; Gong et al. identified shrinking cities in Northeast China with individual-level travel flow data from Baidu Map [10]; Cai et al. used multi-source geospatial big data to identify the multi-center urban spatial structures [11]; Pan and Deal tested the relationship between Chicago's urban transport network and urban structure based on the data of urban land use and POI [12]. Among a variety of urban big data, POI data is gradually favored by many scholars due to the spatial attribute information it contains, a large amount of data collection, and easy access [6]. Jylha employed POI in a multi-mode wearable system for the free exploration of a city [13]; Liu and Andris proposed a POI-based representation learning model to explore place niche patterns [14]; Koohpayma studied the impact radius of POI to direct relationship between some POIs and the occurrence of car park violations through spatial analysis [15]. Some scholars also utilize POI data in urban spatial structure research [16] and urban functional area identification [17]. For example, $\mathrm{Yu}$ et al. identified the urban functional regions of Chengdu based on POI and floating car track data [18]; Jia et al. used the POI and microblog data to analyze the expansion of residential activity space and delimit urban growth boundary in Jinan [19]; Wang et al. identified urban functional regions in Beijing by using POI data and taxi trajectory data [20]. According to the studies of these scholars, most of the research methods on POI data adopt the method of kernel density analysis to explore the spatial aggregation degree, which constructs a plane representing the density change of point group to reflect the urban spatial pattern. The Gibbs-mirtin diversity index can reflect the completeness and diversity of various types of elements in a region. At present, it is mostly used for the analysis of land use structure. Hu et al. [21], Xiang et al. [22], Su [23] all use Gibbs-Mirtin diversity index to quantitatively analyze the characteristics of land use structure in their study areas. The practices of many scholars have proved that POI data can be well used to identify urban spatial structure and functional areas. If the method of kernel density analysis is combined with diversity index method, the spatial aggregation degree, quantity distribution characteristics and category completeness of POI data can be explored more comprehensively. This provides a new possibility and reference for using POI data to study the spatial pattern of urban block development.

After more than half a century of urbanization in China, its speed, the size, and number of cities increased substantially, and cities have become the mainstay for new region development [24,25]. Urbanization involves a lot of aspects such as economy, politics, population, and geographical pattern. While promoting social development, it is also accompanied by a series of ecological, environmental and land use problems [26,27]. Therefore, it is of great significance to understand the current situation of urban spatial pattern, evaluate the trend of urbanization development, study the characteristics of urbanization development, and refine the research on the spatial pattern of urban block development for optimizing the utilization of land resources and guiding the sustainable development of cities [28]. The current urban development in Wuhan has the problem of "overcrowding in the central area and lagging behind of the marginal area". It means that the population in the central city is very dense and the land use pressure, population pressure, employment pressure, and traffic pressure are very high, while the urbanization process in the marginal area is slow with incomplete public service facilities and uneven resource distribution. All these problems need to be solved urgently, so it is extremely important to find a model suitable for the sustainable urban development in Wuhan. The short-term planning objectives proposed in "The 13th Five-Year Plan of Land Use and Spatial Distribution in Wuhan" mentioned that: it is necessary to curb the overpopulation in the main urban areas, to enrich the sparse population in the newly urban groups, and to concentrate the population in rural towns and villages in an orderly manner; on the basis of consolidating the urban spatial pattern of " $1+6$ ", 
it is necessary to implement a new round of overall spatial planning spatial, to highlight the key development directions for the future, and to promote the transformation from " $1+6$ " to " 133 " global urban system [29].(" $1+6$ " means that one main city-center is built within the Third Ring Road and six "satellite cities" of medium-sized city scale guard the main city-center. "133" means that one main city-center within the Third Ring Road, three sub-central districts including Guanggu, Zhuankou, and Lingkong Port, three newly urban groups in the East, South, and west of Wuhan.)

Therefore, by taking Wuhan city as an example, this paper divides the neighborhood according to the road network, uses POI diversity index analysis and kernel density analysis to explore the identification of urban block development stages, and classifies the development stage of urban blocks into three levels: the primary stage, the growth stage, and the maturity stage. Combined with the current situation of land use and the division of administrative streets in Wuhan city, this paper comprehensively analyzes the rationality of the identification of the development stages of the blocks in Wuhan city and its practical significance to urban planning, management, and cognition. At the same time, this paper proposes a concept of urban micro-centers. At present, studies on urban micro-centers in China are still rare, and the model of flattened urban development is still in theoretical exploration. This paper extracts the population density data of Wuhan from the thermal map to find out the urban micro-centers, which is used to verify the accuracy of the identified urban block development stages.

This research will contribute to the understanding of the spatial pattern of urban block development in Wuhan, aiming to find out the block planning and urban spatial pattern suitable for the urban development of Wuhan. This paper explored the spatial pattern and future development trend of urban blocks in Wuhan by identifying the development stage of urban blocks in Wuhan, which was verified by the distribution of urban micro-centers, aiming to form a research model of future urban development in Wuhan through a systematical study on the urban spatial structure. This not only has a great significance for the future urban development of Wuhan, but also could apply to other mega cities, large cities, and medium-sized cities, contributing to the solutions to reduce urban congestion and improve the convenience in residents' life.

\section{Theoretical Framework and Methods}

\subsection{Method for Dividing Urban Blocks}

Divided by urban roads, an urban block is the planar unit that shapes the life of residents and urban environment. An urban block is the basic unit of urban morphological structure, urban function, urban administration, and urban cognition. Therefore, it is of great significance to study the scale of urban block [30]. This paper chooses block as the basic spatial element for urban development stage identification. The administrative scope of a region is divided into multiple blocks based on the road network (including motorway, national road, county road, etc.) [31]. Each block is naturally formed by three levels of roads in ArcGIS (A platform of GIS construction and application).

\subsection{Diversity Index}

The POI Diversity Index is used to analyze the completeness or diversity of various POIs in the studied area, so the Gibbs-Mirtin Diversity Index is used in this paper. This method takes into account the number of POI types and the area of each block. By calculating, we can understand the diversification of POI types and the equilibrium in block development mode in the studied area under certain conditions [23]. The calculation formula for POI Diversity Index is as follows:

$$
G M=1-\sum f_{i}^{2} /\left(\sum f_{i}\right)^{2}
$$

where GM is the diversity index; $f_{i}{ }^{2}$ is the number of the $i$-th POI type. It can be seen from the formula that if there is only one POI type in the studied area, then $\sum f_{i}^{2}=\left(\sum f_{i}\right)^{2}$, which means the diversity 
index is 0 ; if the POI types are more diverse and the development is more balanced in the studied area, the diversity index will be closer to 1 [32].

In this paper, there are two kinds of diversity indices: GM1 represents the diversity index of the primary-level POI in a specific block and GM2 for the diversity index of the secondary level POI, which respectively indicate the equalization degree of the primary-level POIs and the equalization degree of the second-level POIs under a certain primary category in a specific block. The calculation of comprehensive diversity index GM of a block is shown in Equation (2).

$$
G M=k * G M 1+(1-k) * \frac{1}{n} \sum_{n=1}^{n} G M 2 n
$$

where $G M$ is the comprehensive diversity index of a block; GM1 is the diversity index of the primary-level POI in a block; GM2n is the diversity index of the secondary-level POI under the $n$-th category of the primary level; $k$ is the weight of GM1; $n$ is the number of types of primary-level POI.

\subsection{POI Kernel Density Analysis}

Kernel density estimation is a non-parametric estimation method which is mainly applied to the calculation of the density function of random variables. The form of regression function is arbitrary, and the distribution constraints of variables are relatively small, so it has a high level of adaptability [33]. The kernel density estimation function constructs a plane representing the density change of the point group in the studied area through the following steps. At first, place the grid above the studied area and the point group distribution map; then, observe each unit with a moving three-dimensional function and calculate the weight of each point within the search radius; finally, obtain the density of the grid element by calculating the sum of the weight of the circular surface at each position [34]. The calculation formula is as follows:

$$
\lambda(s)=\sum_{i=1}^{n} \frac{1}{\pi r^{2}} k\left(\frac{d_{i s}}{r}\right)
$$

where $\lambda(s)$ represents the density of the point at position $s ; r$ represents the search radius for the kernel density estimation (only the part within the radius of the point entity $\mathrm{r}$ is used to calculate $\lambda(s)$ ); $k$ represents the weight of distance $d_{i s}$ between points $i$ and $s$.

$k$ is usually modeled as a function determined by the ratio of $d_{i s}$ to $r$ (called a kernel function). The kernel density estimation method uses the model function which takes into account the "distance attenuation effect". The weights of all the points within the search radius $(r)$ of point $s$ are determined by their distance from $s$, and finally the density value at $s$ is derived based on the weight of each point. Compared with the function adopting uniform weight for all points within the search radius of $r$, this method could obtain a probability density estimation result that can maintain the overall structural features with high quality [35].Gaussian function, quartic function, and quadratic function are most commonly used as the kernel function to obtain the weight $k$ for the "distance attenuation effect" [36]. In this research, quadratic function in ArcGIS kernel density analysis is adopted due to its simplicity and easy calculation.

\section{Case Study}

\subsection{Study Area and Data}

\subsubsection{Studied Area}

Wuhan, with a total area of $8574.9 \mathrm{~km}^{2}$, is the capital of Hubei Province, located in the eastern part of the Jianghan Plain. The Yangtze River, the third largest river in the world, and its largest tributary, Hanshui, runs through the city of Wuhan, dividing it into "three cities", namely, Wuchang (comprising 
Wuchang District, Qingshan District, and Hongshan District), Hankou (comprising Jianghan District, Jiangan District, and Qiaokou District), and Hanyang (tHanyang District). The above seven central districts constitute the central region of Wuhan. Among them, Hanyang is the early industrial center; Hankou, which has a good industrial and commercial foundation, has developed into an economic and financial center of Wuhan; Wuchang mainly focuses on education and tourism [37]. Around the central city, there are seven suburban and rural districts: Huangpi District, Xinzhou District, Dongxihu District, Caidian District, Hannan District, and Jiangxia District (shown in Figure 1).

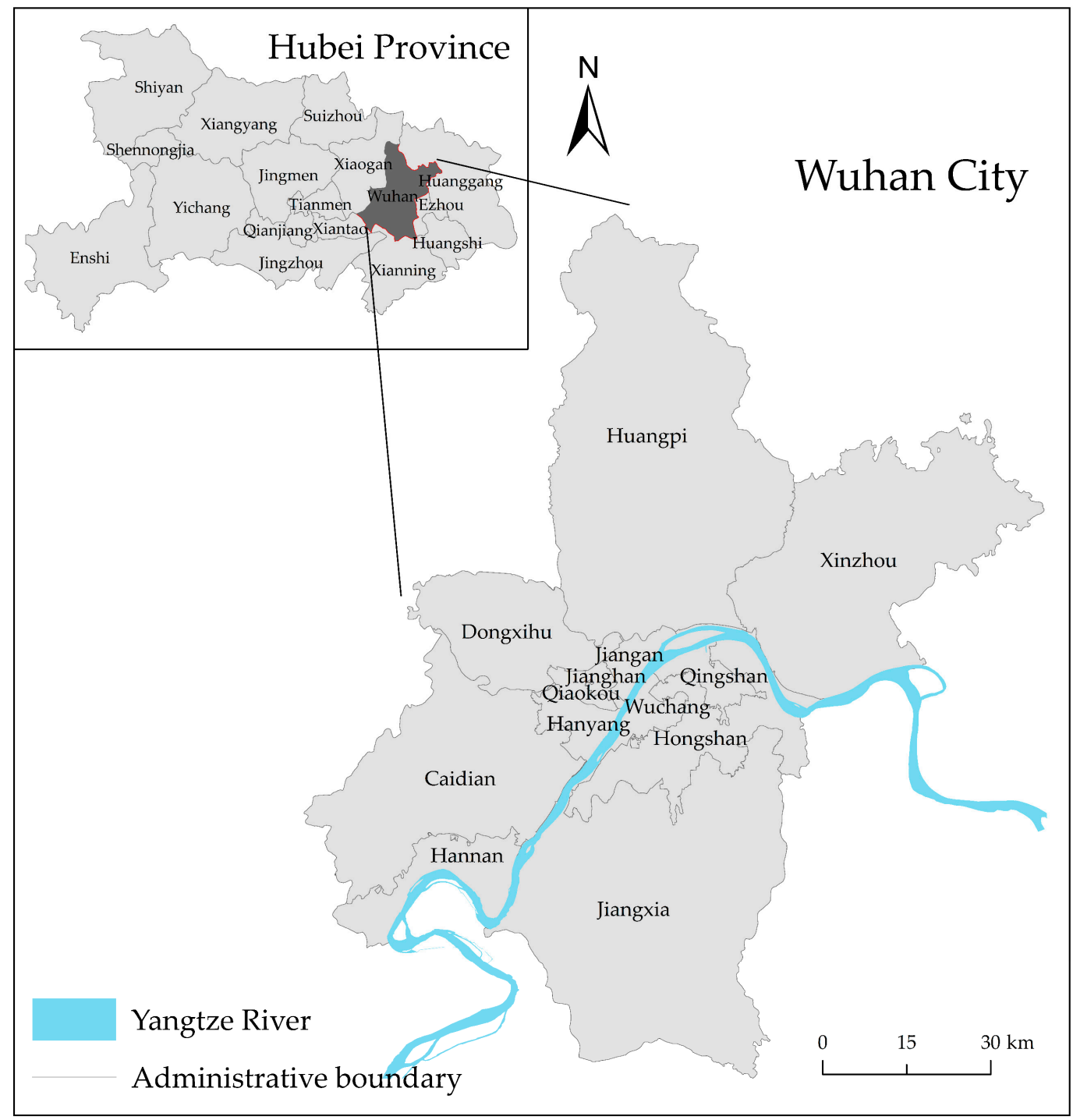

Figure 1. Location map of Wuhan.

\subsubsection{Land Use Status}

This paper employs the 2015 Land use status map and the land use statistics of Wuhan (from Wuhan Natural Resources and Planning Bureau) to analyze the current situation of land use, as shown in Table 1 and Figure 2. According to the statistics, the cultivated land is the largest, which is 3206.13 square kilometers, accounting for $37.48 \%$ of Wuhan's total area; the water area is the second largest, with 2263.79 square kilometers, accounting for $26.46 \%$ of the total area, followed by 1245.28 square kilometers of the construction land, which accounts for $14.56 \%$ of the total area; the unused land area is the smallest, which is about $0.95 \%$ of Wuhan's total area. 
Table 1. Land use status statistics of Wuhan.

\begin{tabular}{ccc}
\hline The Name of Land Category & Area $\left.\mathbf{( k m}^{\mathbf{2}}\right)$ & Proportion of Total Area \\
\hline Cultivated land & 3206.13 & $37.48 \%$ \\
Construction land & 1245.28 & $14.56 \%$ \\
Forest and grassland & 971.028 & $11.35 \%$ \\
Rural settlement & 575.68 & $6.73 \%$ \\
Water & 211.97 & $2.48 \%$ \\
Other land for agricultural production & 2263.79 & $26.46 \%$ \\
Unused land & 81.2125 & $0.95 \%$ \\
\hline
\end{tabular}

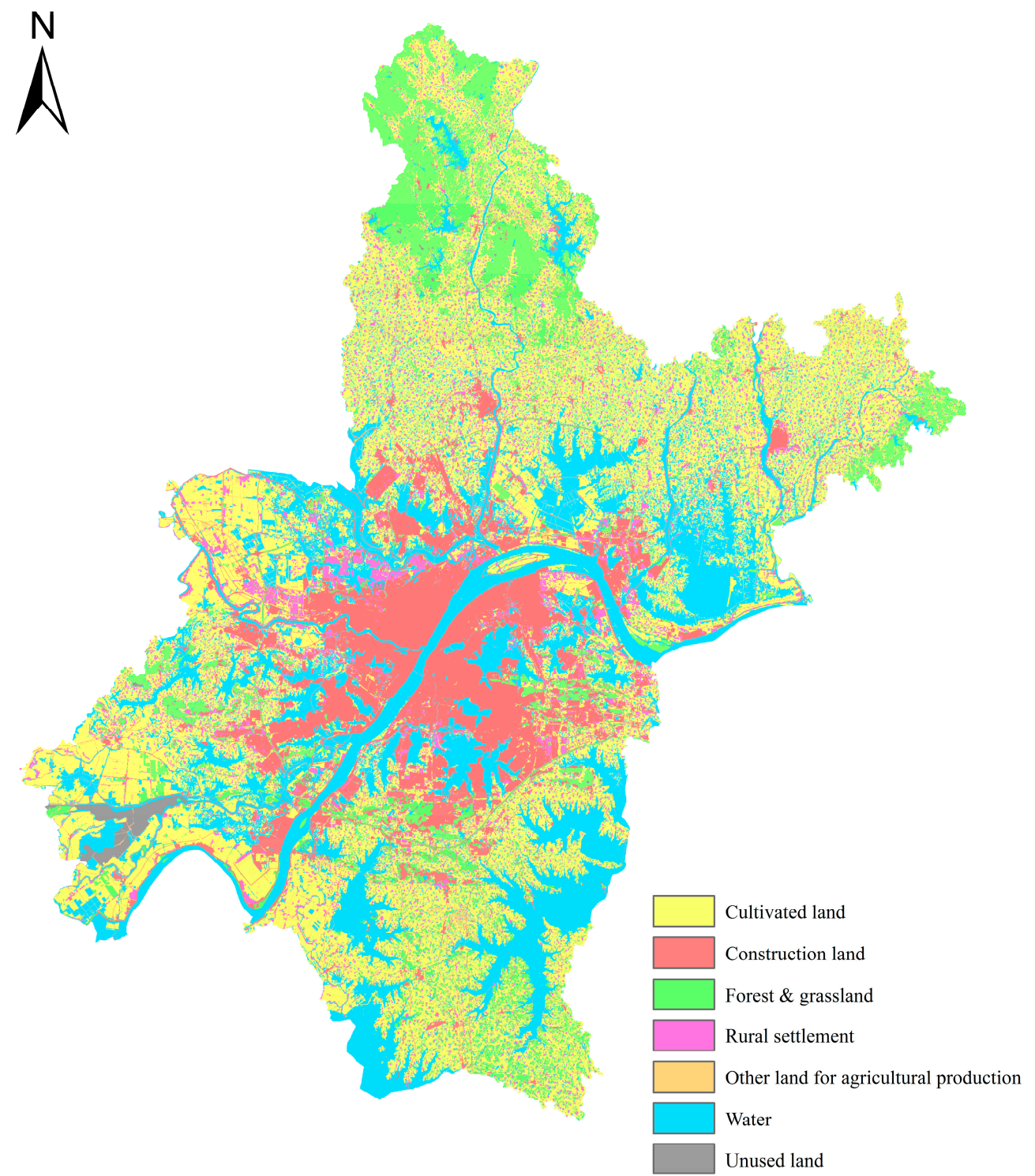

Figure 2. Land use status map of Wuhan.

The construction land mainly distributes in the central urban area of Wuhan, namely, Wuchang, Hankou, and Hanyang, which spreads out along both sides of the Yangtze River. The northern part of Wuhan comprises a large area of cultivated land, forest, and grassland, while the southern and southwestern areas mainly contains water bodies like lake and cultivated land, where the construction land only occupies a small area. 


\subsubsection{Data Preparation}

The POI data of Wuhan employed in this paper was acquired from the Baidu map of 2017 through a $\mathrm{C}++$ program, which has two hierarchical levels. There are 15 categories in the primary level, including catering services, scenic spots, public facilities, companies and enterprises, retail facilities, transportation facilities, financial and insurance services, science, technology and culture organizations, automobile services, business residences, life services, sports and leisure, health care, government agencies, and accommodation services. According to Baidu POI classification, each primary category consists of numerous secondary categories, such as Chinese restaurant, snack bar, fast-food restaurant, bar, supermarket, convenience store, post office, logistics company, park, museum, and cinema [38].

This paper also acquired the remote sensing image of Wuhan, vectorized data (including roads and streets) and the urban thermal map of Wuhan in 2017. The vectorized road network (shown in Figure 3) includes highways, ring roads, branch roads, etc., as well as the data on lakes and rivers in Wuhan. The urban thermal map demonstrates the daily movement of population in Wuhan. The sources and functions of data are shown in Table 2.

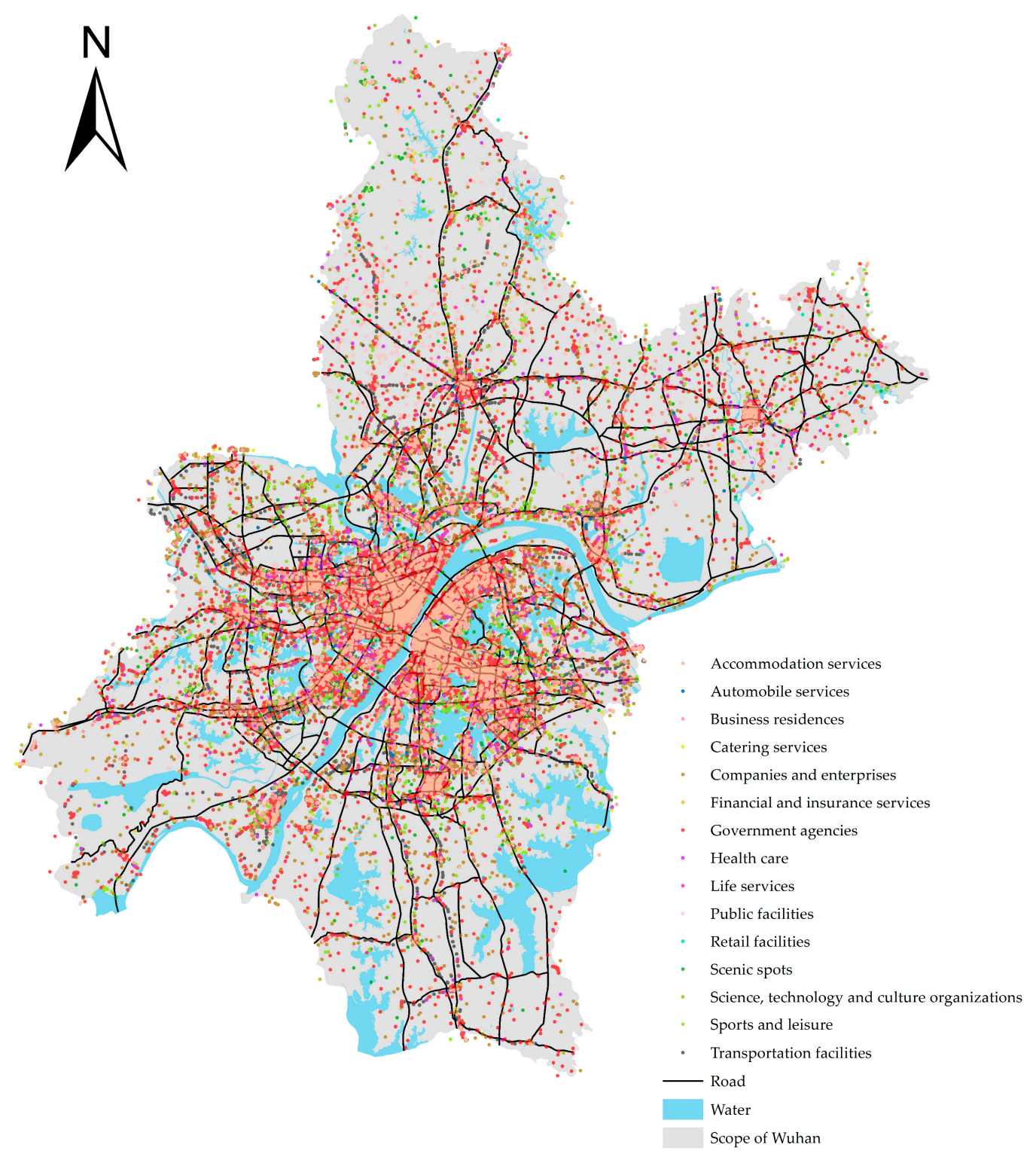

Figure 3. Point of interest (POI), road network, lake distribution map of Wuhan. 
Table 2. Sources and Functions of Data.

\begin{tabular}{ccc}
\hline Data & Source & Function \\
\hline $\begin{array}{c}\text { POI Data of Wuhan } \\
\text { Remote Sensing Image of Wuhan }\end{array}$ & the Baidu Map of 2017 & Calculate Diversity Index and Analyze Kernel Density \\
Vectorized Data & Google Earth & $\begin{array}{l}\text { Interpret and Draw Lakes, Rivers and some Roads in Wuhan } \\
\text { Divide Blocks, Analyze the Geographical Relationship } \\
\text { between Road and POI and Discuss the Urban Development } \\
\text { of Administrative Streets, et al. } \\
\text { Orban Thermal Map of Wuhan }\end{array}$ \\
\hline
\end{tabular}

\subsection{Process of Identifying the Urban Block Development Stage of Wuhan}

\subsubsection{Result of Block Division}

Block is the basic unit shaping residents' life and urban environment, as well as the basic unit of urban morphological structure, urban function, urban administration, and urban cognition. In this paper, urban block is chosen as the basic spatial unit for identifying the stage of urban development, which not only breaks the boundaries between administrative divisions, but also fits well with the present situation that POI distributes along the road network. This approach is more accurate and objective in demonstrating the shape and scope of urban spatial layout than establishing a homogeneous and isotropic spatial grid. According to the method of dividing block units (discussed in Section 2.1), the municipality of Wuhan is divided into multiple blocks based on the road network. After discarding the blocks less than 0.6 square kilometers, 346 urban blocks are generated, as shown in Figure 4.

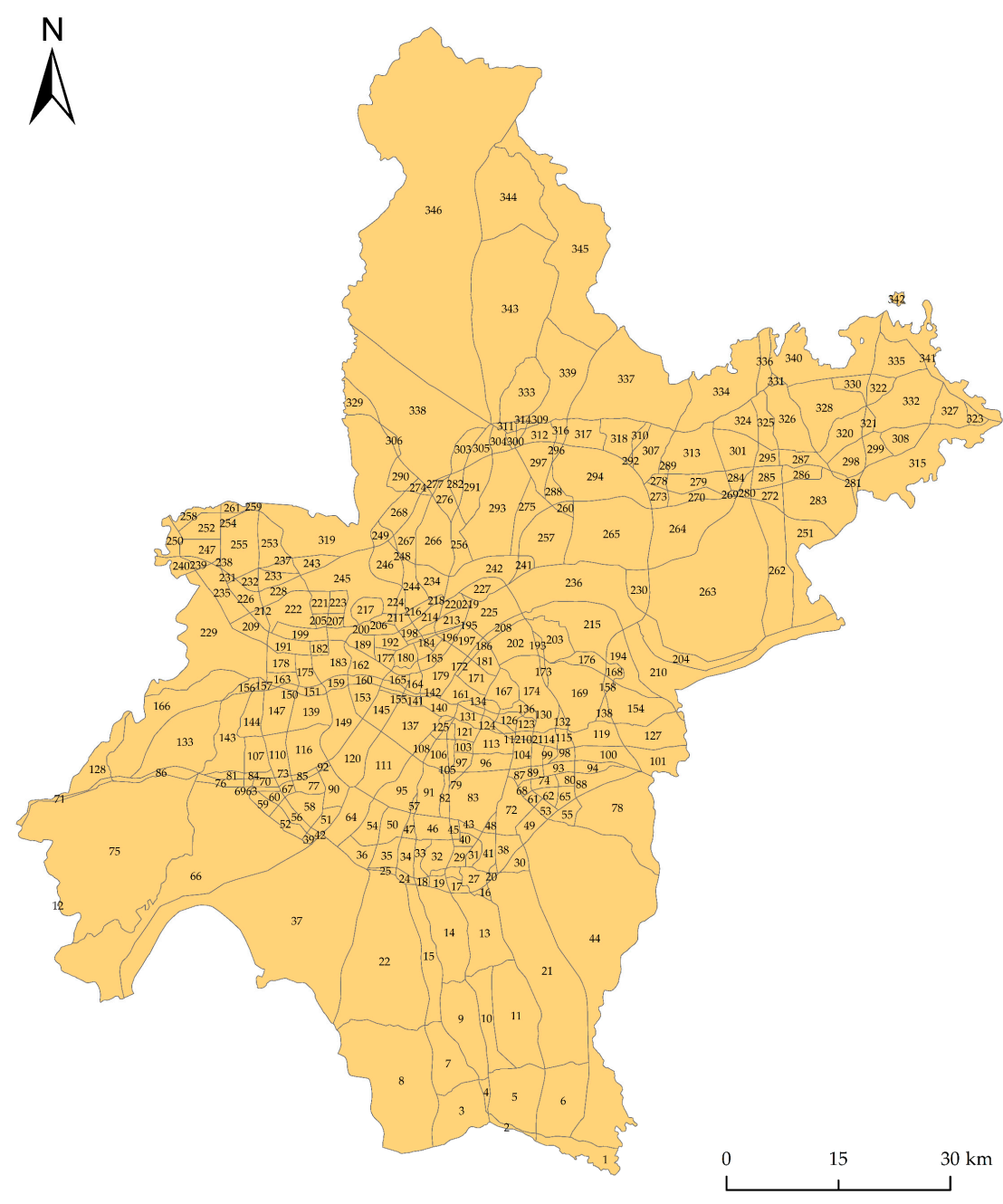

Figure 4. Block map of Wuhan. 


\subsubsection{Result of Comprehensive Diversity Index Calculation}

There are 15 categories of POI in the primary level, and each category has multiple secondary categories (as described in Section 3.1.3). The diversity index is to analyze the diversity of POI types in each block at different levels. According to Equation (2), the weight $k$ is set to 0.7 in order to maximize the regional difference. The diversity index $G M$ which has considered the weights of GM1 and GM2 was used to analyze the diversity of POIs in each block. The numbers of blocks in each section of GM are shown in Figure 5. Nearly 50\% of the blocks have a GM in the $0.8-1$ range, while only $10 \%$ of the blocks have a smaller GM in the 0-0.6 range.

\section{Number of blocks}

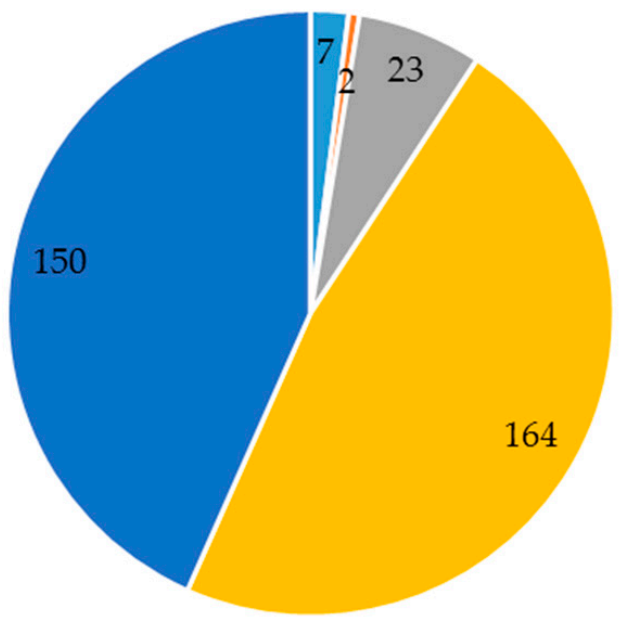

$$
\because 0-0.2=0.2-0.4=0.4-0.6 \quad \square 0.6-0.8 \quad \square 0.8-1
$$

Figure 5. The Numbers of blocks in each section of the diversity index $(G M)$.

\subsubsection{Result of Kernel Density Analysis}

POI data can not only reflect the quantity and type of service hotspots in a region, but also demonstrate its spatial distribution characteristics. However, the quantity of POIs and the diversity index of a block cannot fully explain the urban spatial structure characteristics of a region. Therefore, the kernel density analysis is also carried out in this paper, which is combined with the diversity index analysis to explore the quantity, type, and spatial agglomeration of POIs, which can further reveal the urban development characteristics of a region.

The main purpose of kernel density analysis was to study the spatial distribution of POIs, so this paper didn't classify the POIs when performing kernel density analysis. Instead, kernel density analysis was carried out directly in ArcGIS, and the results were visualized to obtain the map of the spatial distribution of the number of POIs in Wuhan, as shown in Figure 6. In the kernel density analysis, since the number of the POIs in each region differs greatly, in order to display the distribution more comprehensively and accurately, the size of each grid cell was set to 10 and the search radius was set to 800 . The results show that the kernel density of POIs is between 0 and 2665, and the average kernel density of the 346 blocks is between 0 and 1170. In Figure 6, locations with deep color and pockmarks have large POI kernel density and high spatial agglomeration of POIs. The visualization map can clearly demonstrate the characteristics of POI spatial distribution, one of which is that the POI concentration in the downtown area of Wuhan is much higher than that in the suburb. 


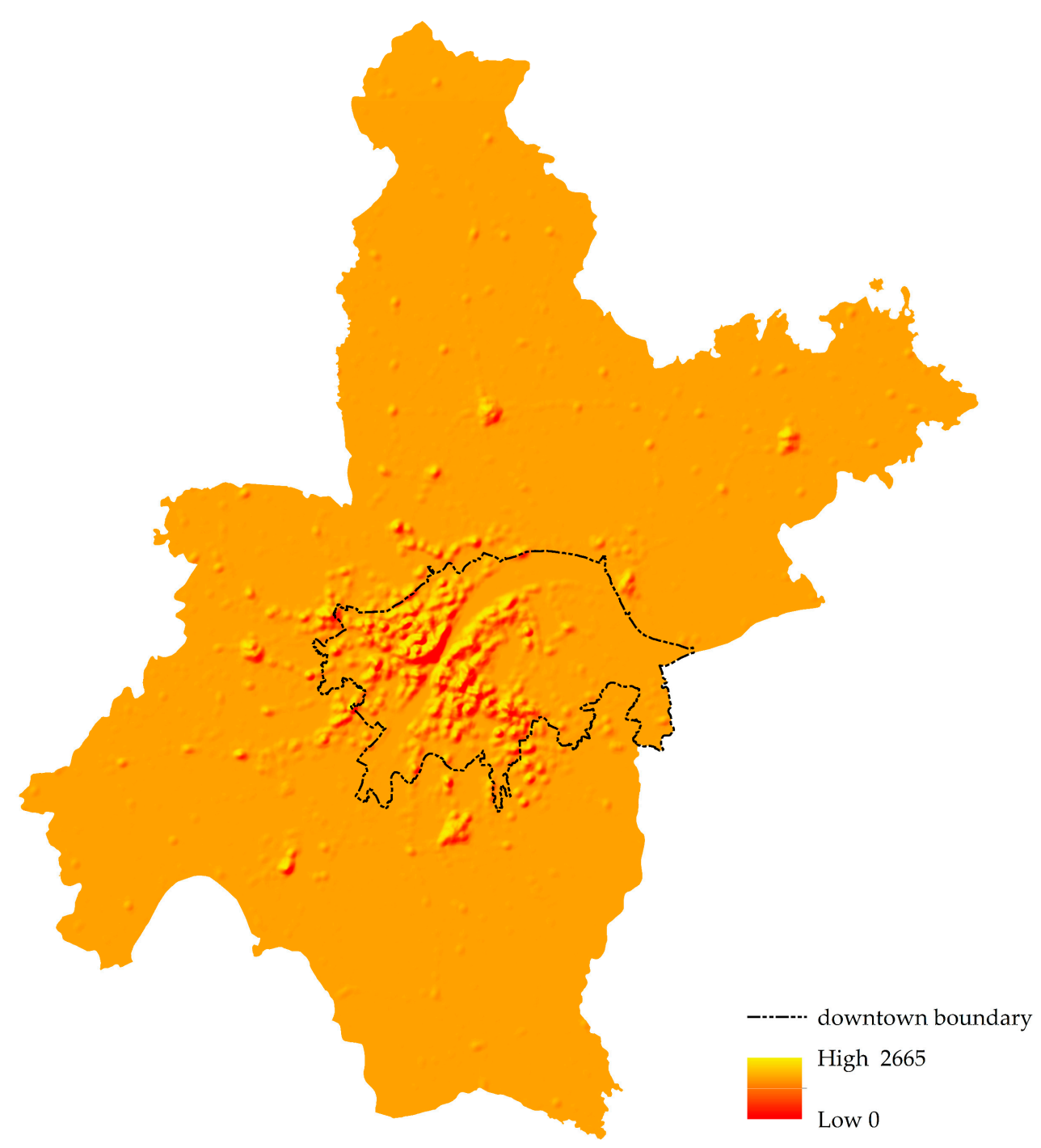

Figure 6. Visualization map of POI spatial distribution in Wuhan.

\subsubsection{Identification of Urban Block Development Stage}

In this paper, the diversity indices and the kernel densities of the POIs in the 346 blocks were used to identify their urban development stage by standardization with the range method. In order to quantify the development stage of urban blocks, the Urban Block Development Index (UBDI) is defined, as shown in Equations (4)-(6):

$$
\begin{gathered}
a=\frac{\lambda-\lambda_{\min }}{\lambda_{\max }-\lambda_{\min }} \times 100 \\
b=\frac{G M-G M_{\min }}{G M_{\max }-G M_{\min }} \times 100 \\
U B D I=\left[1-\left(\frac{a}{b}-1\right)^{2}\right] \times 100
\end{gathered}
$$

where $U B D I$ is the Urban Block Development Index; $a$ is the standardized value of kernel density; $\lambda$ is the kernel density of a block; $b$ is the standardized value of comprehensive diversity index; GM is the comprehensive diversity index of a block. If $\left|\frac{a}{b}-1\right|$ is not within the interval of $[0,1]$, the sample point is an outlier, which needs to be discarded. 
The numerical interval of $U B D I$ is $[0,100]$. The larger the value, the more developed the urban block. In this paper, the UBDIs of 346 blocks are classified in ArcGIS. In the "Natural Breaks (Jenks)" method, Natural Breaks classes are based on natural groupings inherent in the data. Class breaks are identified that best group similar values and that maximize the differences between classes. The features are divided into classes whose boundaries are set where there are relatively big differences in the data values [39]. The "Natural Breaks (Jenks)" method makes the variance between each class maximum and the variance within each class minimum. By using the classification method, UBDI is divided into three stages: the primary stage $[0,16]$, the growth stage $(16,47]$, and the maturity stage of urban block development $(47,100]$. The urban development stages of the 346 blocks in Wuhan are shown in Figure 7.

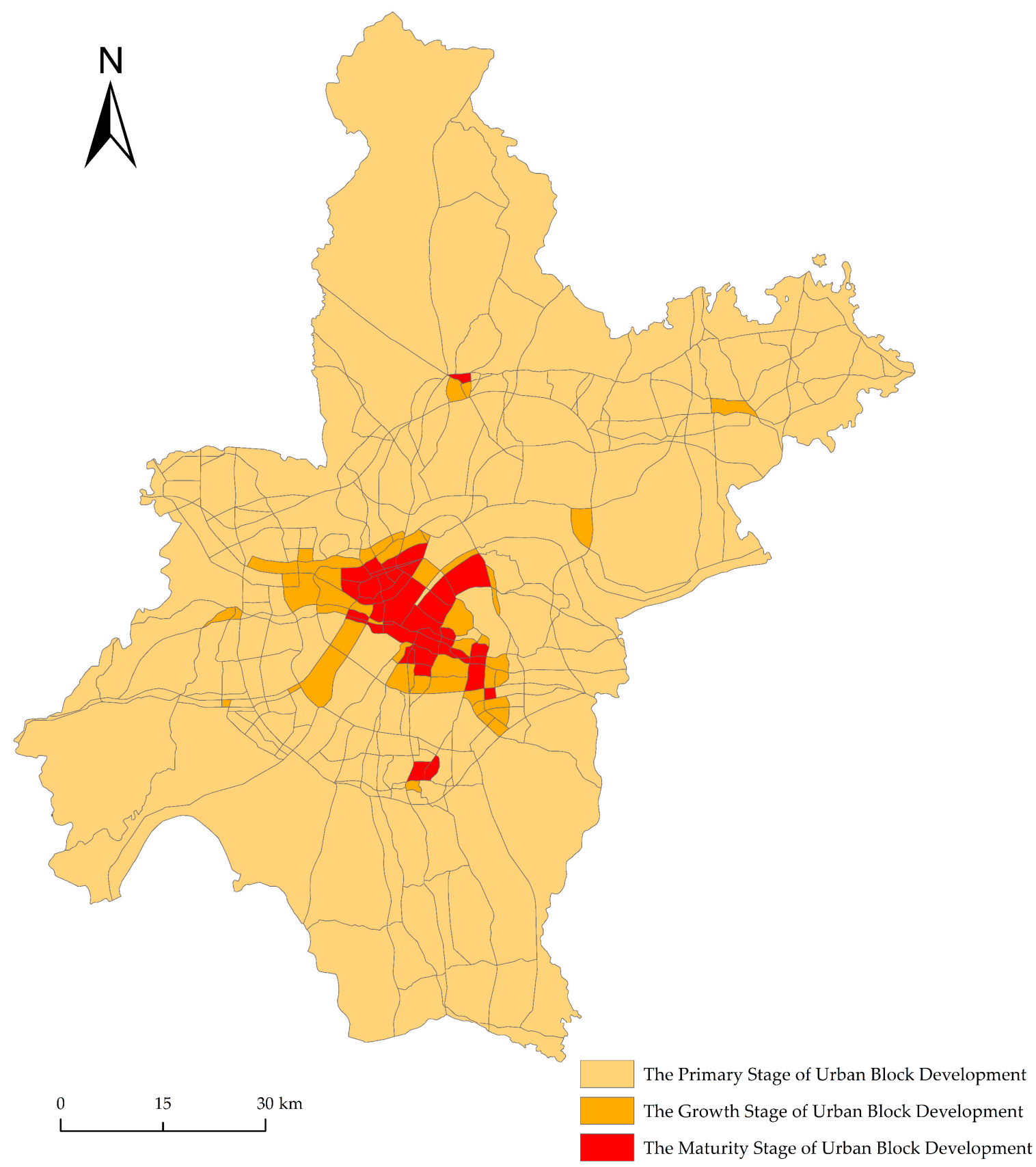

Figure 7. Distribution of urban block development stage of Wuhan. 


\subsection{Identifying Urban Micro-Centers}

An urban micro-center refers to a relatively independent small-scale social center within the city with full urban functions, which can meet the residents' needs for social and public services. The flattened urban development means that the agglomeration of urban functions is no longer restricted by administrative divisions, avoiding the current situation of high agglomeration in the central urban areas. In this pattern, multiple decentralized micro-centers are distributed within the city, forming a flattened and small-scale urban development model. The micro-centers within the city can make residents' lives more convenient, allowing residents to access the nearest public services, employment opportunities, and schools. This can not only alleviate the issues in urban land use, population, employment, and traffic, but also reduce the risk of resource shortage and unequal distribution of public resources.

The distribution of urban micro-centers is mainly affected by population density, while the urban thermal map can reflect the most densely populated areas during each period. This paper extracts the population density of Wuhan at different time of the day according to the urban thermal map of Wuhan (Figure 8), then identifies the current distribution of urban micro-centers in Wuhan through the thermal map, as shown in Figure 9. Through the spatial distribution map, the development stages of the locations of these micro-centers are reviewed to verify the accuracy in the identification of urban development stage, and the blocks are identified which can be preferentially developed into urban micro-centers.

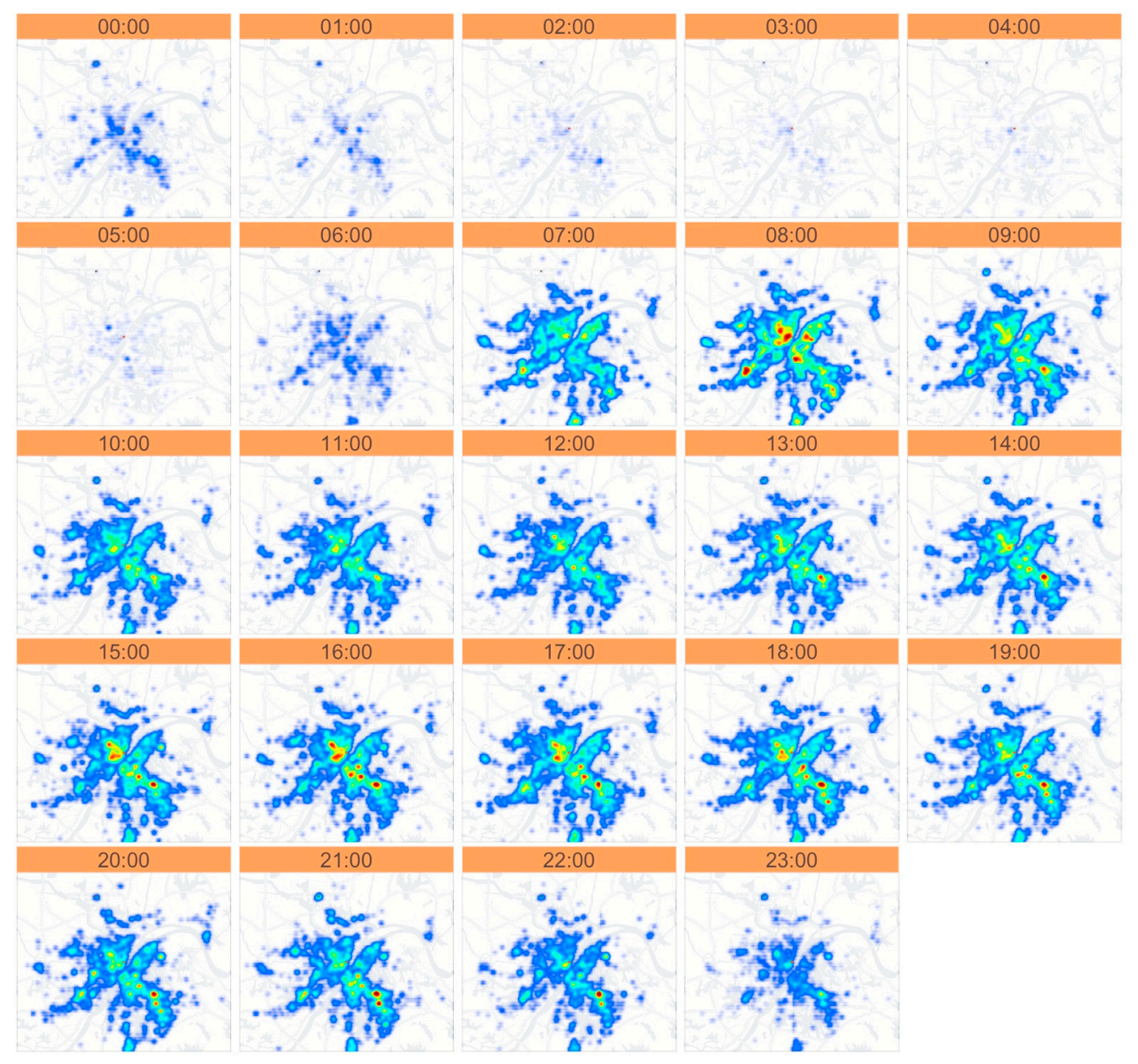

Figure 8. Thermal map at various time in Wuhan. 


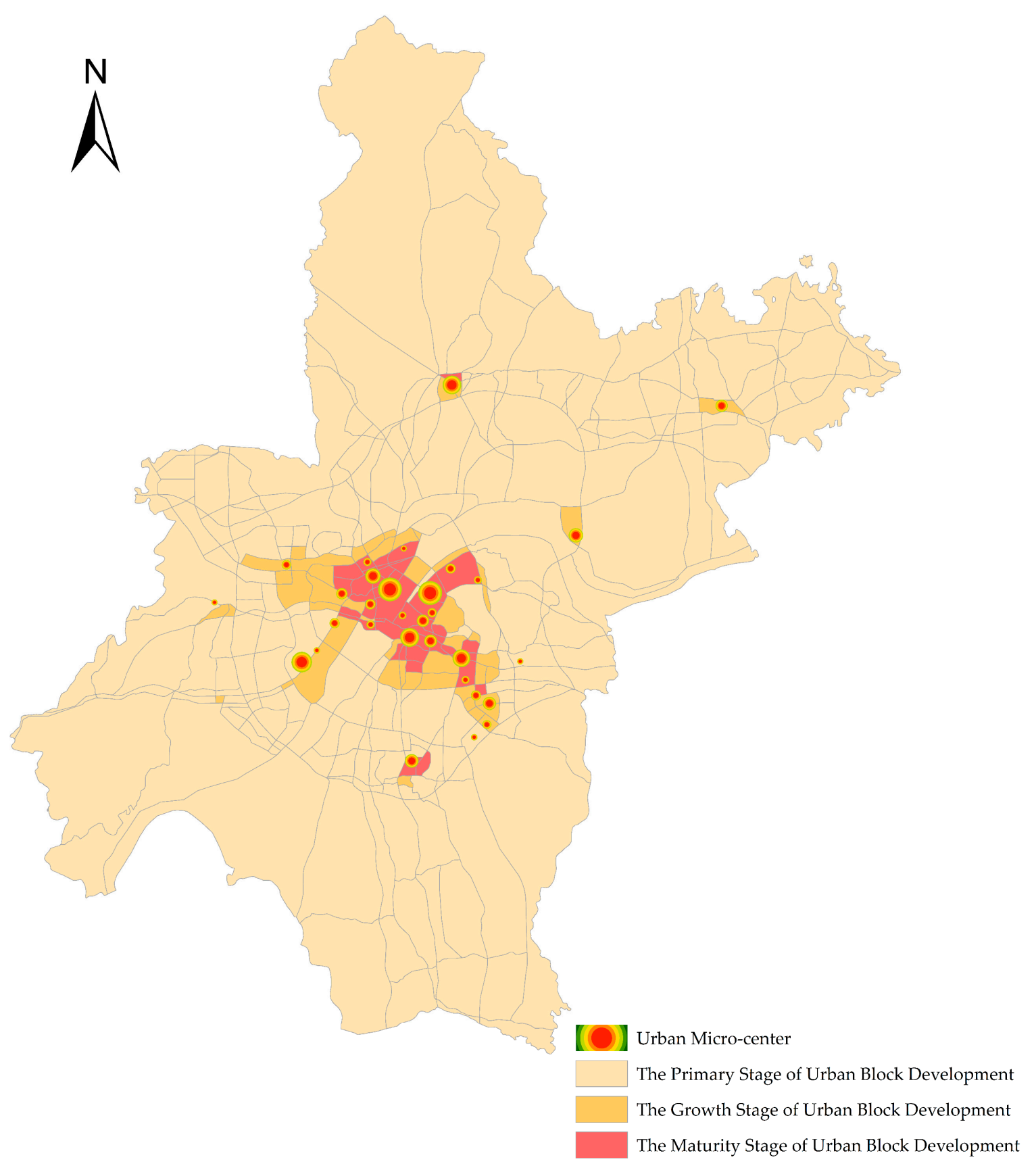

Figure 9. Urban micro-center distribution map of Wuhan.

The research reveals that urban micro-centers are mainly distributed in areas with dense population and high level of economic development. These micro-centers with adequate public services and facilities, already have comprehensive urban functions and high maturity of urban block development. Among them,

(1) the number of urban micro-centers located in the mature urban blocks is relatively large, and the distribution is relatively uniform, which are in line with the characteristics of dense population and large demand for public service facilities in mature blocks;

(2) the number of urban micro-centers located in the blocks at the growth stage is small, and the scope of their influence is limited, but the distribution is uniform, which are in line with the current situation of uniform population distribution and less crowd in the growing blocks; 
(3) there are only three small-scale urban micro-centers are formed in the blocks at the primary development stage, because of the small population density and incomplete urban functions, which reflect the current less developed situation of the marginalized blocks where the flow of people is small.

\section{Discussion}

\subsection{Characteristics of the Spatial Pattern of Urban Block Development in Wuhan}

\subsubsection{The Characteristics of Urban Block Development Stage in Wuhan}

According to the calculation results of GM in Section 3.2.2, the GM of each block is mostly within the range of $0.6-1$, and a few within the range of $0-0.4$. This shows that the infrastructure types of most blocks in Wuhan are evenly distributed, and the functional infrastructure is relatively complete, which has formed the foundation of urban micro center. The urban function of a few blocks is relatively single. According to the analysis of kernel density in Section 3.2.3, the aggregation degree of POI in each block of Wuhan city is quite different, which is much higher in the downtown area than in the marginal area. This shows that the number and scale of urban infrastructure in Wuhan are not evenly distributed. The calculation results of $U B D I$ reveal that the urban block development index of most blocks is very low, and the area in the primary stage accounts for a large proportion, while the mature blocks in the central urban area are relatively dense, and the scale of the blocks at the growth stage cannot keep up with the urban development demand.

According to the results in Section 3.2.4, the distribution characteristics of the urban block development stage in Wuhan are as follows:

(1) Urban blocks at the primary stage of development have the largest area, followed by that at the maturity stage, and the area of the blocks at the growth stage is the smallest.

(2) The maturity of urban block development stage presents the spatial characteristics of "mature blocks concentrated like a core, growth blocks distributed like two wings, and a few mature blocks scattered like stars among primary blocks". (i): The blocks at the maturity stage are concentrated as a core along both sides of the Yangtze River. (ii): The blocks at the growth stage are mainly scattered along the mature blocks to both sides and symmetrically distributed along the Yangtze River, which form the transition zone between the mature and the primary districts. (iii): Some blocks with high maturity are scattered in the surrounding non-central areas, while only two mature districts are scattered in the rural and suburban district of Huangpi and Jiangxia. (iv): The blocks at the primary stage are mainly distributed in other large areas of the non-central areas.

4.1.2. The Spatial Pattern of Urban Block Development is in Accordance with the Present Situation of Land Use

The spatial distribution of urban block development stage reflects the spatial pattern of urban block development. Comparing the identification results of the development stage of urban blocks in Wuhan with the present situation of land use in Wuhan (discussed in Section 3.1.2), the characteristics of the spatial pattern of urban block development can be concluded as follows: The distribution of blocks at the maturity stage and the growth stage is basically consistent with the distribution of construction land; areas with a larger scale of connected construction land tend to have higher the maturity in urban block development, while concentrated cultivated land, forest, grassland, and water are usually distributed in areas with lower stage of urban block development. 
4.1.3. The Consistency Between the Spatial Pattern of Urban Block Development and the Development of Administrative Divisions in Wuhan

In this paper, the division of blocks breaks the traditional boundaries of administrative divisions, which is based on the natural division of roads, and supplemented by artificial division according to the actual situation. In order to compare the identification results of the urban block development stage in Wuhan with the current administrative divisions, this paper superimposes the two for analysis, as shown in Figure 10. The proportion of three types of urban block development stage in each administrative street, is shown in Table 3.

Table 3. The proportion of the area of each development stage in the administrative street of Wuhan. The complete block ranking is shown in Appendix A.

\begin{tabular}{|c|c|c|c|c|}
\hline $\begin{array}{l}\text { Mature } \\
\text { Block }\end{array}$ & $\begin{array}{l}\text { Growth } \\
\text { Block }\end{array}$ & $\begin{array}{l}\text { Primary } \\
\text { Block }\end{array}$ & $\begin{array}{l}\text { Street } \\
\text { Number }\end{array}$ & Street Name \\
\hline $100 \%$ & $0 \%$ & $0 \%$ & 36 & $\begin{array}{l}\text { Baofeng Street, Beihu Street, Changqing Street, Chezhan Street, } \\
\text { Dazhi Street, Ganghuacun Street, Hanzheng Street, } \\
\text { Hanzhong Street, Hualou Street, Huaqiao Street, etc. } \\
\text { Zhangiiawan Street, Jivuqiao Street, Zivang Road Street. }\end{array}$ \\
\hline $50-99 \%$ & - & - & 17 & $\begin{array}{l}\text { Hanxing Street, Shouyi Road Street, Xujiapeng Street, } \\
\text { Jianqiao Street, etc. }\end{array}$ \\
\hline $1-49 \%$ & - & - & 25 & $\begin{array}{l}\text { Erqi Street, Changfeng Village, Hanjiadun Street, Yingwu Street, } \\
\text { Luonan Street, Qinduankou Street, Jianghan Erqiao Street, } \\
\text { Yangyuan Street, etc. }\end{array}$ \\
\hline $0 \%$ & $100 \%$ & $0 \%$ & 4 & $\begin{array}{l}\text { Yijiadun Street, Shidong Street, Wujiashan Street, } \\
\text { Changqing Garden New Area }\end{array}$ \\
\hline $0 \%$ & $50-99 \%$ & - & 1 & Sixin New Area \\
\hline $0 \%$ & $1-49 \%$ & - & 16 & $\begin{array}{l}\text { Yongfeng Village, Changqing Street, Cihui Street, } \\
\text { Jiangjun Road Street, Zhuankou Street, Jinyinhu Street, } \\
\text { Jinghe Street, Caidian Street, etc. }\end{array}$ \\
\hline $0 \%$ & $0 \%$ & $100 \%$ & 69 & $\begin{array}{l}\text { Baiyushan Street, Chenjiaji Street, Huashan Street, } \\
\text { Jianshe Village, QIngshan Town Street, Tianxing Street, } \\
\text { Wudong Street, Zhoutou Street, Zuoling Town, } \\
\text { Xingouzhen Street, etc. }\end{array}$ \\
\hline
\end{tabular}

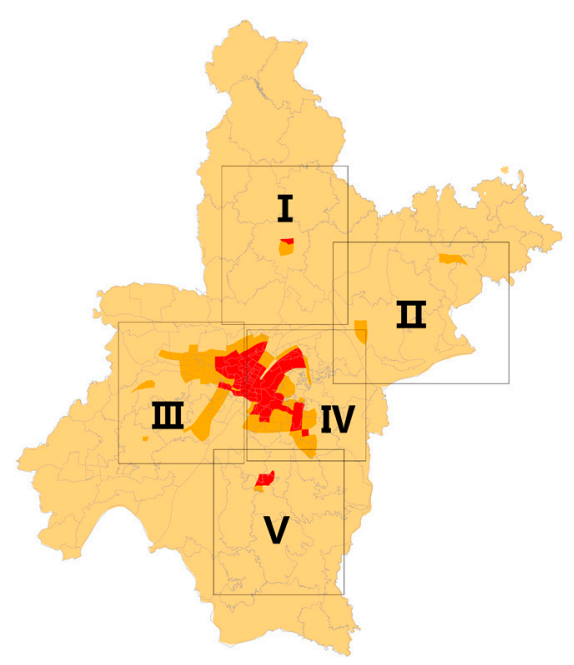

(a)

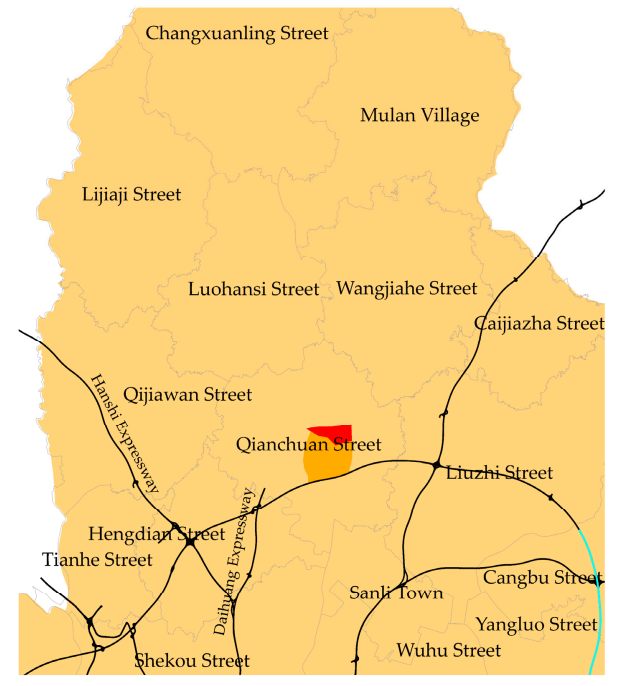

(b)

Figure 10. Cont. 


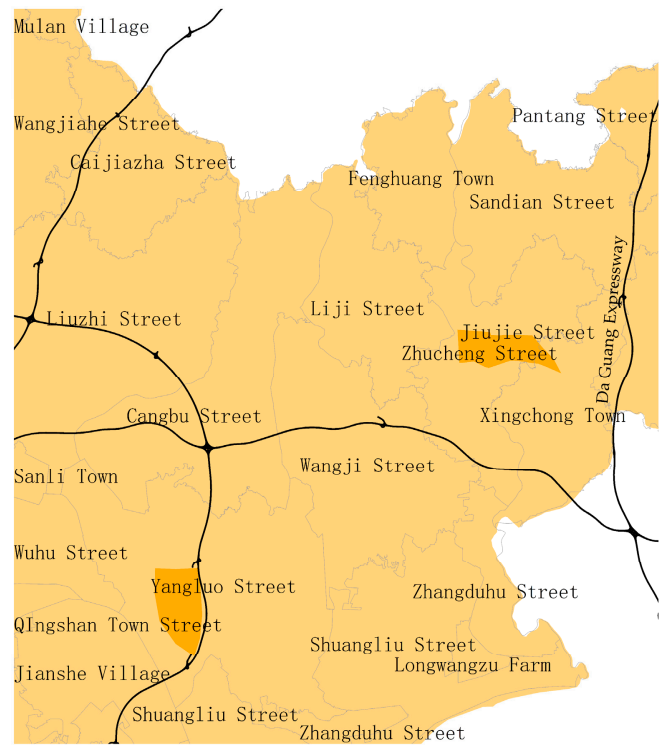

(c)

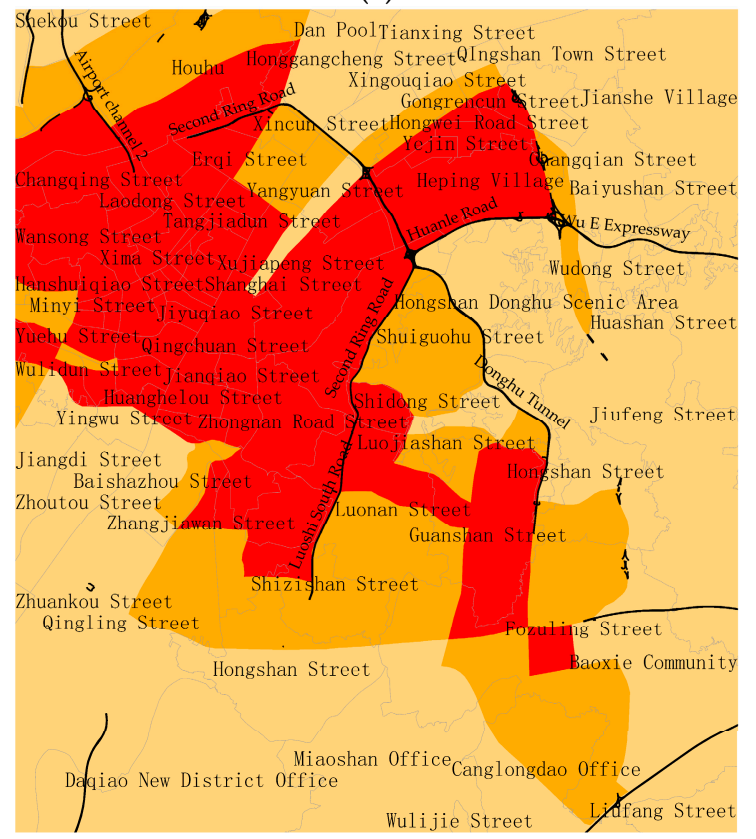

(e)

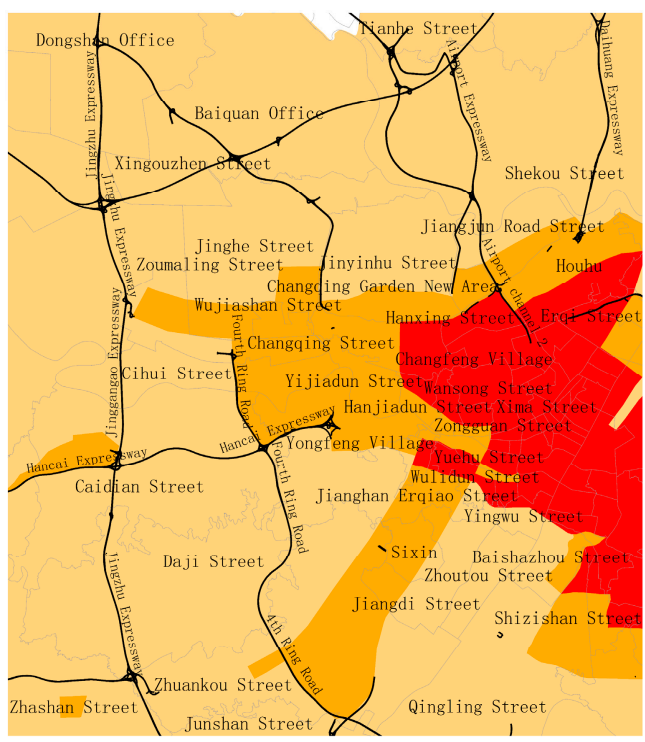

(d)

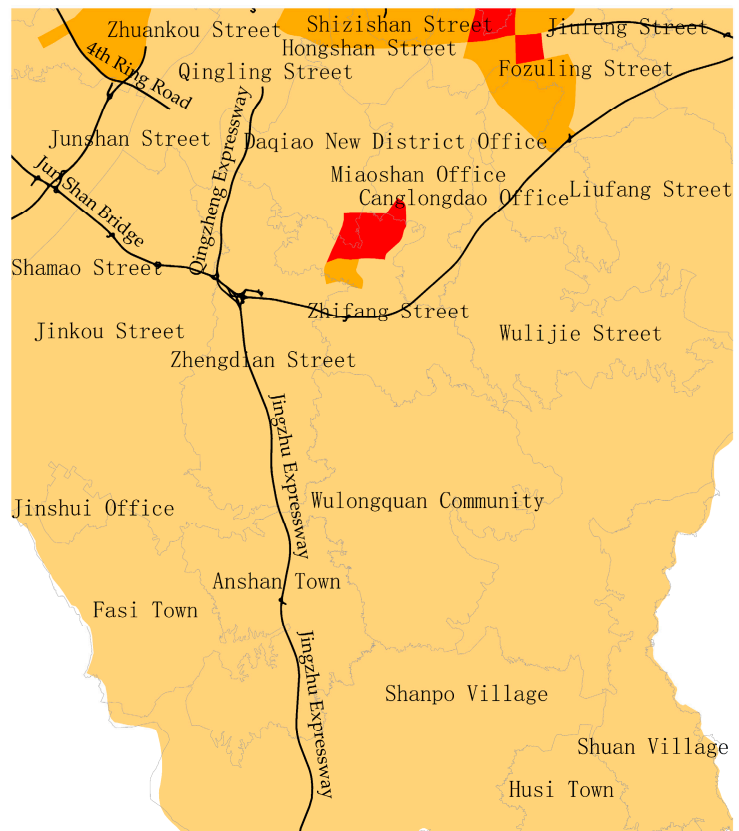

(f)

Figure 10. Street and block area overlay of Wuhan. (a) The street and block area overlay of Wuhan as a whole; (b) the street and block area overlay of Wuhan part I; (c) the street and block area overlay of Wuhan part II; (d) the street and block area overlay of Wuhan part III; (e) the street and block area overlay of Wuhan part IV; (f) the street and block area overlay of Wuhan part V.

The urban blocks with high maturity are mainly located in Wuchang District, the midwest of Hongshan District, Jianghan District, the east of Qiaokou District, the south of Jiangan District, and the northeast of Hanyang District, while the blocks with low maturity are mainly in the six non-central districts. The spatial distribution of the urban block development stage in Wuhan is basically consistent with the current socio-economic development status of the areas in Wuhan. Therefore, one of the main characteristics of the spatial pattern of urban block development is that areas with better socio-economic development tend to have the higher maturity in urban block development, and vice versa. The blocks at the maturity stage are all located in the areas with dense population, high level of urbanization, good economy and stable economic development such as Zhongnan Road, 
Zhonghua Road, Yongqing Street, etc.; the blocks at the growth stage are located in the areas with mediate level of urbanization and economic conditions and rapid economic development, such as Shizishan Street, Guandong Street, Baishazhou Street, etc.; the blocks at the primary stage are widely located in the areas with low level of urbanization and backward economic conditions, such as Gongrencun Street, Jiufeng Street, Bajifu Street, etc.

According to the proportion of three types of urban block development stage in each street, It can be concluded that in addition to the mature blocks in the central urban area and the large-scale primary blocks in the edge area, some streets cover 2-3 kinds of urban block development stages, inside which the development differs greatly. The internal development of the street is not balanced, but the management and planning of the same street are consistent, which leads to a situation that is easy to cause contradictions among residents: residents living in the same street at different stages of development get equal welfare from the government. Meanwhile, the current road distribution according to street planning is not balanced, which leads to a series of problems such as traffic congestion in Wuhan. The block division is based on the road segmentation, which is helpful to improve the road density and lay a good foundation for the realization of urban flat development. Therefore, it is of great benefit to divide the urban development stage based on blocks, break the shackle of administrative streets and make reasonable planning.

4.1.4. The Matching Between the Spatial Pattern of Urban Block Development and the Distribution of Micro-centers in Wuhan

According to the comparison between the results of urban micro-centers identification and urban block development stage in Wuhan, the following characteristics of spatial pattern of urban block development can be obtained:

1. The spatial pattern of urban block development matches the geographical distribution of micro-centers

There are a total of 31 urban micro-centers in Wuhan identified in this paper, which have a geographical overlap with the following streets. Among them,

(1) 17 streets are located in urban blocks at the maturity stage of development, including Jiyuqiao Street, Xujiapeng Street, Shouyi Street, Zhongnan Road Street and Shuiguohu Street in Wuchang District, Hanxing Street, Changqing Street, Tangjiadun Street, Xinhua Street, Shuita Street and Qianjin Street in Jianghan District, Houhu Street, Taibei Street, Xima Street, Qiuchang Street, Dazhi Street and Chezhan Street in Jiangan District, Luonan Street, Guanshan Street and Heping Village in Hongshan District, Ronghua Street and Baofeng Street in Qiaokou District; Cuiwei street in Hanyang District, and Ganghuacun street in Qingshan District;

(2) There are 10 streets located in urban blocks at the growth stage of development, including Wujiashan Street in Dongxihu District, Hanjiadun Street in Qiaokou District; Fozuling Street in Jiangxia District, Yangluo Street and Yecheng Street in Xinzhou District, and Qianchuan Street in Huangpi District;

(3) There are 4 streets located in urban blocks at the primary stage of development, including Zhuankou Street and Caidian Street in Caidian District, Jiufeng Street in Hongshan District, and Canglongdao Office in Jiangxia District.

These streets overlapped by micro-centers are located in the flat terrain, and compared with the surrounding streets, they are more prosperous, with larger flow of people and stronger economic development potential, which is consistent with the characteristics of micro-centers as independent small social centers.

It can be concluded that the geographical distribution of micro-centers in Wuhan is in line with the spatial pattern of urban block development. The streets overlapped with the micro-centers are consistent with the streets distributed in the blocks at the maturity stage. The higher the maturity of the block is, the more the number of micro-centers is and the larger the range of its influence is. 
2. The spatial pattern of urban block development matches the distribution of micro-centers in the development trend

In this paper, the urban block development stage reflects the current level of urbanization in Wuhan, while the urban micro-center reflects the future development trend of urbanization in Wuhan. The spatial pattern of urban block development is composed of three stages of spatial distribution, and urban micro-centers are identified based on the urban thermal map. Both of them are compatible with the development trend of the city, which is embodied in:

(1) In the future, the spatial pattern of urban block development in Wuhan will promote the transformation of blocks from the growth stage to the mature stage and the primary stage to the growth stage. Therefore, improving the maturity of the blocks at the primary stage and growth stage is the key point of urban development in Wuhan in the future.

(2) Urban micro-centers have a significant impact on the surrounding blocks, which can alleviate the overpopulation in the blocks at the maturity stage and promote the urbanization process of the immature blocks. These are all in line with the short-term planning objectives proposed in "The 13th Five-Year Plan of Land Use and Spatial Distribution in Wuhan" (discussed in Section 1), which are supported by macro policies.

(3) Balancing the number of micro-centers at different stages is the key to promote the flattened urban development of Wuhan in the future. The flattened urban development represents the formation of multiple evenly distributed urban micro centers in the whole region. The urban pressure is no longer concentrated in the downtown area, and the marginal areas can also get more development opportunities. The infrastructure of the urban micro-centers is full of functions and the employment opportunities are abundant, which attract people to disperse to the marginal areas of the city for more comfortable living environment. Therefore, the flattened urban development is the main pattern of urban block development in the future.

4.1.5. Application and Universality of the Study on the Spatial Pattern of Urban Block Development in Wuhan

The identification results of the urban block development stage match the current land use situation, the development status of streets and the distribution of urban micro-centers, which verifies the feasibility of the research method and the reliability of the conclusion of the spatial pattern of urban block development in Wuhan. At present, the biggest spatial characteristics of the spatial pattern of urban block development in Wuhan are the high maturity in the central urban area and the low maturity of the blocks in the surrounding urban areas. This further validates the existing problems of urban development in Wuhan, "overcrowding in the central area and lagging behind of the marginal area". It means that the exploration on the spatial pattern of urban block development in Wuhan is of practical significance and can be applied in practice. At the same time, after verification, the method of identifying the development stage of urban blocks in this paper can also be applicable to Nanjing, Zhengzhou, Chengdu and other big Chinese cities. Therefore, the research method is also applicable to the study of the spatial pattern of urban block development in other cities.

\subsection{Suggestions on the Spatial Pattern of Urban Block Development in Wuhan}

Due to the historical and other reasons, the government has been committed to the rapid development of the central area of the city, resulting in the urban development of the outer suburbs of Wuhan falling far behind. This is not conducive to the achievement of the development goal of high level of urbanization of Wuhan city, or to the overall urbanization development of Hubei Province. The spatial pattern of urban block development in Wuhan reflects that the blocks at the maturity stage are highly concentrated in a small area; the development of blocks at the growth stage is highly dependent on the mature blocks and its progress is slow; the area of the blocks at the primary stage is large and far away from mature blocks and their development faces many challenges. 
At present, some big cities in China have created urban block planning based on road network, such as Beijing [40], Suzhou [41], Shanghai [42,43], etc. The urban development in Singapore [44] and New York [45] relies on the high-density road network, forming multiple relatively homogeneous small-scale blocks, and multi-centers. Flattened urban planning could be crucial to the future urban development, and the urban block based micro-center could be the main form of urban planning. Therefore, the optimization strategies for the future urban block development pattern in Wuhan are (i): avoiding the aging of mature urban blocks and promoting the three-dimensional urban space, (ii): promoting the economic development in multiple urban regions and the urbanization of peripheral areas, (iii): improving road density and regulating block roads, and building more roads between blocks, (iv): dividing urban micro-centers to realize the flattened urban development.

In order to facilitate the future urbanization and optimize the spatial pattern of urban block development in Wuhan, this paper proposes the following suggestions.

(1) The blocks at the maturity stage need to disperse the urban pressure to the surrounding blocks with low maturity, so as to control the continuous expansion of the number and scope of the micro-centers at this stage, especially for block 131,171,179, 181, 184, 185, and 187, corresponding to Taibei Street, Xima Street, Qiuchang Street, Dazhi Street and Chezhan Street in Jiangan District, Changqing Street and Tangjiadun Street in Jianghan District, Xujiapeng Street, Shouyi Road Street, and Zhongnan Road Street in Wuchang District.

(2) The number of urban micro-centers at the growth stage is small, so the scope of such micro-centers needs to be expanded in the future and a number of small-scale micro-centers need to be formed around them to share the pressure of the micro-centers in the mature blocks, particularly for block 199, 230, 287, 300, and 304, corresponding to Wujiashan Street, Qianchuan Street, Yangluo Street, and Zhucheng Street.

(3) The number of urban micro-centers located in the primary stage is the least. In the future, their development should be emphasized by building infrastructure, improving urban functional facilities, accelerating the progress of urbanization, and laying a solid foundation for the realization of the flattened urban development, especially in Hannan District where micro-centers have not been formed.

\section{The Significance of Exploring the Spatial Pattern of Urban Block Development}

(1) The identification of urban block development stage plays a complementary role in the layout design of urban micro-center. The identification of urban block development stage is necessary to generate the layout of urban micro-centers, and the layout design of urban micro-centers is the upgrade of the identification of urban block development stage. The identification of urban block development stage provides support and innovation of technical methods for the layout of urban micro-centers. The block identification obtained through the big data analysis of POI eliminates statistical errors of data to a certain extent, which is more objective and real. Through deep mining of data, it provides accurate data reference for the layout design of urban micro-centers. At the same time, the identification of urban block development stage is based on the unit of small-scale block, which provides a detailed and precise support for the refinement of the layout of urban micro-centers.

(2) This study can not only contribute to the understanding of the urban development status and issues in Wuhan, but also provide a scheme for the future urban planning and urban spatial structure optimization and adjustment in Wuhan, making urbanization research more systematic and comprehensive. The concept of "urban micro-center" provides a new idea for the optimization of the spatial pattern of urban block development in the future. The development model could boost the urbanization in Wuhan in the future. Exploring the spatial pattern of urban block development provides theoretical and technical support for the development of "smart city" in Wuhan. 
(3) The spatial pattern of urban block development derived from the spatial distribution of urban block development stage is of great value to urban planning and the determination of urban land use The block identification based on big data can clearly reflect the characteristics and problems of the spatial pattern of urban block development with its accuracy reaching the scale of block, so that urban planning can be implemented at the level of blocks. Moreover, it breaks the boundaries of administrative divisions and achieves the consistency in urban planning cross the boundaries. The spatial pattern of urban block development clarifies the overall trend of urban land use, and provides specific reference for the refinement of urban land use in the future.

(4) The method for exploring the spatial pattern of urban block development adopted in this paper could be applicable to the urban development research for mega-cities, large cities, and medium-sized cities. This method can not only present the issues and characteristics of urban development clearly through spatial visualization, but also provide an important reference for the development of modern cities in the new era. A new solution to the problem of space congestion and unbalanced development is put forward, namely, the model of flattened urban development. It is of great significance to a series of problems such as the aging of urban blocks, the backward development of marginal areas and the overcrowding in urban areas. Therefore, the significance of exploring the spatial pattern of urban block development in this paper is extensive. The research methods are applicable, and the research conclusions are of practical significance and important value.

\section{Conclusions and Future Research}

Based on the POI diversity index and kernel density analysis, this paper identifies the urban block development stage in Wuhan, and explores the spatial pattern of urban blocks. It is concluded that the central areas in Wuhan on both sides of the Yangtze River have high mature urban blocks, comprehensive urban functions, and dense urban micro-centers, but some blocks in the old urban areas are aging; however, the non-central areas with a large area of immature blocks, low urbanization level and small number of urban micro-centers, which is not conducive to urban expansion. Therefore, this paper puts forward the concept of "flattened urban development" and some suggestions on the future urban development in Wuhan.

This research on the identification of urban block development stage is feasible and necessary in practice. The exploration of the spatial pattern of urban block development can be used as the basis for further researches on the optimization of urban structure, the identification of urban functional areas and the improvement of urban functional layout. Through the study of the division of blocks, the block division will be more humanized and rational. By identifying the urban micro-centers, the future urban planning of Wuhan is clearer. This study is suitable for mega-cities, large cities, and medium-sized cities, which are in the rapid stage of urban development and unbalanced situation of internal development. This research can provide more scientific and reasonable technical support and services for urban management and planning, macro decision-making, public services, and "smart city" construction [46].

At present, there are also some problems in POI data. For example, in some special areas, such as tourist attractions and university campuses which occupy a larger area, POI distribution is sparse, which will lead to the misidentification of the POI density of blocks. In future studies, the accuracy of big data should be strengthened for the refinement of the spatial pattern of urban block development. At the same time, other big data may be used to supplement other aspects of urban spatial structure analysis, such as the identification of urban functional area, the optimization of urban road network and the identification of urban-rural intersection boundary, etc. A complete set of models for future urban development research is expected to be formed and applied to the systematic study of urban spatial structure in various cities. 
Author Contributions: Conceptualization, J.Z. and H.X.; methodology, J.Z. and H.X.; software, H.X.; validation, H.X., J.Z. and Z.W.; formal analysis, H.X.; investigation, H.X.; resources, J.Z. and Z.W.; data curation, H.X.; writing-original draft preparation, H.X.; writing—review and editing, H.X. and J.Z.

Funding: This research was supported by the National Natural Science Foundation of China (Grant No. 71673258).

Acknowledgments: The authors are grateful to the editors and the anonymous reviewers for their insightful comments and suggestions.

Conflicts of Interest: The authors declare no conflicts of interest.

\section{Appendix A}

Table A1. The proportion of the area of the development of each city block in each street of Wuhan.

\begin{tabular}{|c|c|c|c|c|}
\hline Street Name & Mature Block & Growth Block & Primary Block & Maturity Ranking \\
\hline Zhongnan Road Street & $100 \%$ & $0 \%$ & $0 \%$ & 1 \\
\hline Zhonghua Road Street & $100 \%$ & $0 \%$ & $0 \%$ & 2 \\
\hline Yongqing Street & $100 \%$ & $0 \%$ & $0 \%$ & 3 \\
\hline Yiyuan Street & $100 \%$ & $0 \%$ & $0 \%$ & 4 \\
\hline Yejin Street & $100 \%$ & $0 \%$ & $0 \%$ & 5 \\
\hline Xinhua Street & $100 \%$ & $0 \%$ & $0 \%$ & 6 \\
\hline Xima Street & $100 \%$ & $0 \%$ & $0 \%$ & 7 \\
\hline Wansong Street & $100 \%$ & $0 \%$ & $0 \%$ & 8 \\
\hline Tangjiadun Street & $100 \%$ & $0 \%$ & $0 \%$ & 9 \\
\hline Taibei Street & $100 \%$ & $0 \%$ & $0 \%$ & 10 \\
\hline Siwei Street & $100 \%$ & $0 \%$ & $0 \%$ & 11 \\
\hline Shuita Street & $100 \%$ & $0 \%$ & $0 \%$ & 12 \\
\hline Shanghai Street & $100 \%$ & $0 \%$ & $0 \%$ & 13 \\
\hline Ronghua Street & $100 \%$ & $0 \%$ & $0 \%$ & 14 \\
\hline Qiuchang Street & $100 \%$ & $0 \%$ & $0 \%$ & 15 \\
\hline Qingchuan Street & $100 \%$ & $0 \%$ & $0 \%$ & 16 \\
\hline Qianjin Street & $100 \%$ & $0 \%$ & $0 \%$ & 17 \\
\hline Minzu Street & $100 \%$ & $0 \%$ & $0 \%$ & 18 \\
\hline Minyi Street & $100 \%$ & $0 \%$ & $0 \%$ & 19 \\
\hline Minquan Street & $100 \%$ & $0 \%$ & $0 \%$ & 20 \\
\hline Manchun Street & $100 \%$ & $0 \%$ & $0 \%$ & 21 \\
\hline Luojiashan Street & $100 \%$ & $0 \%$ & $0 \%$ & 22 \\
\hline Liujiaoting Street & $100 \%$ & $0 \%$ & $0 \%$ & 23 \\
\hline Liangdao Street & $100 \%$ & $0 \%$ & $0 \%$ & 24 \\
\hline Laodong Street & $100 \%$ & $0 \%$ & $0 \%$ & 25 \\
\hline Huanghelou Street & $100 \%$ & $0 \%$ & $0 \%$ & 26 \\
\hline Huaqiao Street & $100 \%$ & $0 \%$ & $0 \%$ & 27 \\
\hline Hualou Street & $100 \%$ & $0 \%$ & $0 \%$ & 28 \\
\hline Hanzhong Street & $100 \%$ & $0 \%$ & $0 \%$ & 29 \\
\hline Hanzheng Street & $100 \%$ & $0 \%$ & $0 \%$ & 30 \\
\hline Ganghuacun Street & $100 \%$ & $0 \%$ & $0 \%$ & 31 \\
\hline Dazhi Street & $100 \%$ & $0 \%$ & $0 \%$ & 32 \\
\hline Chenzhan Street & $100 \%$ & $0 \%$ & $0 \%$ & 33 \\
\hline Changqing Street & $100 \%$ & $0 \%$ & $0 \%$ & 34 \\
\hline Beihu Street & $100 \%$ & $0 \%$ & $0 \%$ & 35 \\
\hline Baofeng Street & $100 \%$ & $0 \%$ & $0 \%$ & 36 \\
\hline Zhangjiawan Street & $95 \%$ & $5 \%$ & $0 \%$ & 37 \\
\hline Jiyuqiao Street & $95 \%$ & $5 \%$ & $0 \%$ & 39 \\
\hline Ziyanglu Street & $95 \%$ & $0 \%$ & $5 \%$ & 38 \\
\hline Hanxing Street & $91 \%$ & $9 \%$ & $0 \%$ & 40 \\
\hline Shouyi Road Street & $89 \%$ & $11 \%$ & $0 \%$ & 41 \\
\hline Xujiapeng Street & $88 \%$ & $3 \%$ & $9 \%$ & 42 \\
\hline Jianqiao Street & $87 \%$ & $13 \%$ & $0 \%$ & 43 \\
\hline Cuiwei Street & $83 \%$ & $17 \%$ & $0 \%$ & 44 \\
\hline Shuiguohu Street & $76 \%$ & $16 \%$ & $8 \%$ & 45 \\
\hline Guanshan Street & $74 \%$ & $26 \%$ & $0 \%$ & 46 \\
\hline Zongguan Street & $69 \%$ & $31 \%$ & $0 \%$ & 47 \\
\hline Wulidun Street & $68 \%$ & $11 \%$ & $21 \%$ & 48 \\
\hline Chongren Street & $67 \%$ & $33 \%$ & $0 \%$ & 49 \\
\hline Yuehu Street & $64 \%$ & $36 \%$ & $0 \%$ & 50 \\
\hline Hanshuiqiao Street & $60 \%$ & $40 \%$ & $0 \%$ & 51 \\
\hline Xincun Street & $53 \%$ & $47 \%$ & $0 \%$ & 52 \\
\hline
\end{tabular}


Table A1. Cont.

\begin{tabular}{|c|c|c|c|c|}
\hline Street Name & Mature Block & Growth Block & Primary Block & Maturity Ranking \\
\hline Heping Village & $51 \%$ & $14 \%$ & $35 \%$ & 53 \\
\hline Erqi Street & $48 \%$ & $52 \%$ & $0 \%$ & 54 \\
\hline Changfeng Village & $47 \%$ & $53 \%$ & $0 \%$ & 55 \\
\hline Hanjiadun Street & $46 \%$ & $54 \%$ & $0 \%$ & 56 \\
\hline Yingwu Street & $44 \%$ & $0 \%$ & $56 \%$ & 57 \\
\hline Luonan Street & $43 \%$ & $57 \%$ & $0 \%$ & 58 \\
\hline Qinduankou Street & $33 \%$ & $67 \%$ & $0 \%$ & 59 \\
\hline Jianghanerqiao Street & $33 \%$ & $50 \%$ & $17 \%$ & 60 \\
\hline Houhu & $32 \%$ & $45 \%$ & $23 \%$ & 61 \\
\hline Yangyuan Street & $30 \%$ & $41 \%$ & $30 \%$ & 62 \\
\hline Shizishan Street & $27 \%$ & $73 \%$ & $0 \%$ & 63 \\
\hline Xingouqiao Street & $18 \%$ & $45 \%$ & $36 \%$ & 64 \\
\hline Hongwei Road Street & $17 \%$ & $33 \%$ & $50 \%$ & 65 \\
\hline Gongrencun Street & $14 \%$ & $0 \%$ & $86 \%$ & 66 \\
\hline Honggangcheng Street & $14 \%$ & $36 \%$ & $50 \%$ & 67 \\
\hline Zhifang Street & $12 \%$ & $3 \%$ & $85 \%$ & 68 \\
\hline Baishazhou Street & $9 \%$ & $31 \%$ & $60 \%$ & 69 \\
\hline Fozuling Street & $7 \%$ & $40 \%$ & $53 \%$ & 70 \\
\hline Danshuichi & $7 \%$ & $12 \%$ & $82 \%$ & 71 \\
\hline Daqiao New District Office & $4 \%$ & $0 \%$ & $96 \%$ & 72 \\
\hline Hongshan Donghu Scenic Area & $3 \%$ & $49 \%$ & $48 \%$ & 73 \\
\hline Qianchuan Street & $2 \%$ & $7 \%$ & $91 \%$ & 74 \\
\hline Miaoshan Office & $2 \%$ & $2 \%$ & $96 \%$ & 75 \\
\hline Jiangdi Street & $1 \%$ & $25 \%$ & $73 \%$ & 76 \\
\hline Hongshan Street & $1 \%$ & $26 \%$ & $73 \%$ & 77 \\
\hline Qingling & $1 \%$ & $12 \%$ & $87 \%$ & 78 \\
\hline Yijiadun Street & $0 \%$ & $100 \%$ & $0 \%$ & 79 \\
\hline Wujiashan Street & $0 \%$ & $100 \%$ & $0 \%$ & 80 \\
\hline Shidong Street & $0 \%$ & $100 \%$ & $0 \%$ & 81 \\
\hline Changqing Garden New Area & $0 \%$ & $100 \%$ & $0 \%$ & 82 \\
\hline Sixin & $0 \%$ & $78 \%$ & $22 \%$ & 83 \\
\hline Yongfeng Village & $0 \%$ & $49 \%$ & $51 \%$ & 84 \\
\hline Changqing Street & $0 \%$ & $49 \%$ & $51 \%$ & 85 \\
\hline Cihui Street & $0 \%$ & $32 \%$ & $68 \%$ & 86 \\
\hline Jiangjun Road Street & $0 \%$ & $32 \%$ & $68 \%$ & 87 \\
\hline Dunkou Street & $0 \%$ & $31 \%$ & $69 \%$ & 88 \\
\hline Jinyinhu Street & $0 \%$ & $22 \%$ & $78 \%$ & 89 \\
\hline Jinghe Street & $0 \%$ & $19 \%$ & $81 \%$ & 90 \\
\hline Canglongdao Office & $0 \%$ & $17 \%$ & $83 \%$ & 91 \\
\hline Caidian Street & $0 \%$ & $10 \%$ & $90 \%$ & 92 \\
\hline Zhucheng Street & $0 \%$ & $9 \%$ & $91 \%$ & 93 \\
\hline Changqian Street & $0 \%$ & $9 \%$ & $91 \%$ & 94 \\
\hline Yangluo Street & $0 \%$ & $8 \%$ & $92 \%$ & 95 \\
\hline Xinchong Town & $0 \%$ & $2 \%$ & $98 \%$ & 96 \\
\hline Yuxian Town & $0 \%$ & $2 \%$ & $98 \%$ & 97 \\
\hline LushanStreet & $0 \%$ & $1 \%$ & $99 \%$ & 98 \\
\hline Jiufeng & $0 \%$ & $1 \%$ & $99 \%$ & 99 \\
\hline Baiyushan Street & $0 \%$ & $0 \%$ & $100 \%$ & 100 \\
\hline Chenjiaji Street & $0 \%$ & $0 \%$ & $100 \%$ & 101 \\
\hline Huashan Street & $0 \%$ & $0 \%$ & $100 \%$ & 102 \\
\hline Jianshe Village & $0 \%$ & $0 \%$ & $100 \%$ & 103 \\
\hline QIngshan Town Street & $0 \%$ & $0 \%$ & $100 \%$ & 104 \\
\hline Tianxing Street & $0 \%$ & $0 \%$ & $100 \%$ & 105 \\
\hline Wudong Street & $0 \%$ & $0 \%$ & $100 \%$ & 106 \\
\hline Zhoutou Street & $0 \%$ & $0 \%$ & $100 \%$ & 107 \\
\hline Zuoling Town & $0 \%$ & $0 \%$ & $100 \%$ & 108 \\
\hline Xingouzhen Street & $0 \%$ & $0 \%$ & $100 \%$ & 109 \\
\hline Baiquan Office & $0 \%$ & $0 \%$ & $100 \%$ & 110 \\
\hline Dongshan Office & $0 \%$ & $0 \%$ & $100 \%$ & 111 \\
\hline Xinandu Office & $0 \%$ & $0 \%$ & $100 \%$ & 112 \\
\hline Zoumaling Street & $0 \%$ & $0 \%$ & $100 \%$ & 113 \\
\hline Shamao Street & $0 \%$ & $0 \%$ & $100 \%$ & 114 \\
\hline Dongjing Street & $0 \%$ & $0 \%$ & $100 \%$ & 115 \\
\hline Xiangkou Street & $0 \%$ & $0 \%$ & $100 \%$ & 116 \\
\hline
\end{tabular}


Table A1. Cont.

\begin{tabular}{|c|c|c|c|c|}
\hline Street Name & Mature Block & Growth Block & Primary Block & Maturity Ranking \\
\hline Dengnan Street & $0 \%$ & $0 \%$ & $100 \%$ & 117 \\
\hline Yongan Street & $0 \%$ & $0 \%$ & $100 \%$ & 118 \\
\hline Zhuru Street & $0 \%$ & $0 \%$ & $100 \%$ & 119 \\
\hline Daji Street & $0 \%$ & $0 \%$ & $100 \%$ & 120 \\
\hline Zhangwan Street & $0 \%$ & $0 \%$ & $100 \%$ & 121 \\
\hline Junshan Street & $0 \%$ & $0 \%$ & $100 \%$ & 122 \\
\hline Suohe Town & $0 \%$ & $0 \%$ & $100 \%$ & 123 \\
\hline Xiaosi Village & $0 \%$ & $0 \%$ & $100 \%$ & 124 \\
\hline Tonghu Farm & $0 \%$ & $0 \%$ & $100 \%$ & 125 \\
\hline Hongbei Management Committee & $0 \%$ & $0 \%$ & $100 \%$ & 126 \\
\hline Jinkou Street & $0 \%$ & $0 \%$ & $100 \%$ & 127 \\
\hline Wulongquan Community & $0 \%$ & $0 \%$ & $100 \%$ & 128 \\
\hline Zhengdian Street & $0 \%$ & $0 \%$ & $100 \%$ & 129 \\
\hline Liufang Street & $0 \%$ & $0 \%$ & $100 \%$ & 130 \\
\hline Wulijie Street & $0 \%$ & $0 \%$ & $100 \%$ & 131 \\
\hline Baoxie Community & $0 \%$ & $0 \%$ & $100 \%$ & 132 \\
\hline Fasi Town & $0 \%$ & $0 \%$ & $100 \%$ & 133 \\
\hline Anshan Town & $0 \%$ & $0 \%$ & $100 \%$ & 134 \\
\hline Husi Town & $0 \%$ & $0 \%$ & $100 \%$ & 135 \\
\hline Shanpo Village & $0 \%$ & $0 \%$ & $100 \%$ & 136 \\
\hline Shuan Village & $0 \%$ & $0 \%$ & $100 \%$ & 137 \\
\hline Jinshui Office & $0 \%$ & $0 \%$ & $100 \%$ & 138 \\
\hline Liangzihu Scenic Area Management Committee & $0 \%$ & $0 \%$ & $100 \%$ & 139 \\
\hline Qijiawan Street & $0 \%$ & $0 \%$ & $100 \%$ & 140 \\
\hline Hengdian Street & $0 \%$ & $0 \%$ & $100 \%$ & 141 \\
\hline Luohansi Street & $0 \%$ & $0 \%$ & $100 \%$ & 142 \\
\hline Shekou Street & $0 \%$ & $0 \%$ & $100 \%$ & 143 \\
\hline Liuzhi Street & $0 \%$ & $0 \%$ & $100 \%$ & 144 \\
\hline Tianhe Street & $0 \%$ & $0 \%$ & $100 \%$ & 145 \\
\hline Wuhu Street & $0 \%$ & $0 \%$ & $100 \%$ & 146 \\
\hline Yaojiaji Street & $0 \%$ & $0 \%$ & $100 \%$ & 147 \\
\hline Caijiazha Street & $0 \%$ & $0 \%$ & $100 \%$ & 148 \\
\hline Wangjiahe Street & $0 \%$ & $0 \%$ & $100 \%$ & 149 \\
\hline Lijiaji Street & $0 \%$ & $0 \%$ & $100 \%$ & 150 \\
\hline Changxuanling Street & $0 \%$ & $0 \%$ & $100 \%$ & 151 \\
\hline Sanli Town & $0 \%$ & $0 \%$ & $100 \%$ & 152 \\
\hline Caidian Village & $0 \%$ & $0 \%$ & $100 \%$ & 153 \\
\hline Mulan Village & $0 \%$ & $0 \%$ & $100 \%$ & 154 \\
\hline Cangbu Street & $0 \%$ & $0 \%$ & $100 \%$ & 155 \\
\hline Wangii Street & $0 \%$ & $0 \%$ & $100 \%$ & 156 \\
\hline Liji Street & $0 \%$ & $0 \%$ & $100 \%$ & 157 \\
\hline Sandian Street & $0 \%$ & $0 \%$ & $100 \%$ & 158 \\
\hline Pantang Street & $0 \%$ & $0 \%$ & $100 \%$ & 159 \\
\hline Jiujie Street & $0 \%$ & $0 \%$ & $100 \%$ & 160 \\
\hline Shuangliu Street & $0 \%$ & $0 \%$ & $100 \%$ & 161 \\
\hline Xugu Town & $0 \%$ & $0 \%$ & $100 \%$ & 162 \\
\hline Fenghuang Town & $0 \%$ & $0 \%$ & $100 \%$ & 163 \\
\hline Guandaohe Scenic Area & $0 \%$ & $0 \%$ & $100 \%$ & 164 \\
\hline Zhangduhu Street & $0 \%$ & $0 \%$ & $100 \%$ & 165 \\
\hline Longwangzu Farm & $0 \%$ & $0 \%$ & $100 \%$ & 166 \\
\hline
\end{tabular}

\section{References}

1. Yu, W.H.; Ai, T.H. Network Kernel Density Estimation for the Analysis of Facility POI Hotspots. Acta Geod. Cartogr. Sin. 2015, 44, 1378-1383.

2. Xu, X.Q.; Zhou, Y.X.; Ning, Y.M. Urban Geography; Higher Education Press: Beijing, China, 1997.

3. Bailey, T.C.; Gatrell, A.C. Interactive Spatial Data Analysis; Longman: Harlow, UK, 1995.

4. Schabenberger, O.; Gotway, C.A. Statistical Methods for Spatial Data Analysis; Chapman \& Hall/CRC: Boca Raton, FL, USA, 2005.

5. Chen, F.; Du, D.S. Application of the Integration of Spatial Statistical Analysis with GIS to the Analysis of Regional Economy. Geomat. Inf. Sci. Wuhan Univ. 2002, 27, 391-396. 
6. Yang, Z.J.; He, X.; Sui, X.; Zhang, J. Analysis of the Evolution of Urban Center Space Based on POI: A Case Study of Main Area in Kunming. Urban Dev. Stud. 2019, 26, 31-35.

7. Wang, N.C.; Liu, Y.F.; Wang, J.Z.; Qian, X.J.; Zhao, X.Z.; Wu, J.P.; Wu, B.; Yao, S.J.; Fang, L. Investigating the Potential of Using POI and Nighttime Light Data to Map Urban Road Safety at the Micro-Level: A Case in Shanghai, China. Sustainability 2019, 11, 4739. [CrossRef]

8. Feng, D.Y.; Tu, L.L.; Sun, Z.W. Research on Population Spatiotemporal Aggregation Characteristics of a Small City: A Case Study on Shehong County Based on Baidu Heat Maps. Sustainability 2019, 11, 6276. [CrossRef]

9. Yue, W.Z.; Chen, Y.; Zhang, Q.; Liu, Y. Spatial explicit assessment of urban vitality using multi-source data: A case of Shanghai, China. Sustainability 2019, 11, 638. [CrossRef]

10. Gong, Z.; Tao, R.; Ma, Q.; Kan, C. Exploratory Analysis of Inter-City Human Activity Interactions for Shrinking Cities in Northeast China with flow AMOEBA. In Proceedings of the 26th GIScience Research UK Conference, Leicester, UK, 17-20 April 2018.

11. Cai, J.; Huang, B.; Song, Y. Using multi-source geospatial big data to identify the structure of polycentric cities. Remote Sens. Environ. 2017, 202, 210-221. [CrossRef]

12. Pan, H.Z.; Deal, B.; Chen, Y. A Reassessment of Urban Structure and Land-use Patterns: Distance to CBD or Network-based?-Evidence from Chicago. Reg. Sci. Urban Econ. 2018, 70, 215-228. [CrossRef]

13. Jylha, A.; Hsieh, Y.T.; Orso, V. A Wearable Multimodal Interface for Exploring Urban Points of Interest. In Proceedings of the 2015 ACM International Conference on Multimodal Interaction (ICMI'15), Seattle, WA, USA, 9-13 November 2015; pp. 175-182.

14. Liu, X.; Andris, C.; Rahimi, S. Place niche and its regional variability: Measuring spatial context patterns for points of interest with representation learning. Comput. Environ. Urban Syst. 2019, 75, 146-160. [CrossRef]

15. Koohpayma, J.; Tahooni, A.; Jelokhani-Niaraki, M.; Arsanjani, J.J. Spatial Analysis of Curb-Park Violations and Their Relationship with Points of Interest: A Case Study of Tehran, Iran. Sustainability 2019, 11, 6336. [CrossRef]

16. Deng, Y.; Liu, J.P.; Liu, Y.; Luo, A. Detecting Urban Polycentric Structure from POI Data. ISPRS Int. Geo Inf. 2019, 8, 283. [CrossRef]

17. Zhai, W.; Bai, X.Y.; Shi, Y.; Han, Y.; Peng, Z.R.; Gu, C.L. Beyond Word2vec: An approach for urban functional region extraction and identification by combining Place2vec and POIs. Comput. Environ. Urban Syst. 2019, 74, 1-12. [CrossRef]

18. Yu, B.B.; Wang, Z.H.; Mu, H.W.; Sun, L.; Hu, F.N. Identification of Urban Functional Regions Based on Floating Car Track Data and POI Data. Sustainability 2019, 11, 6541. [CrossRef]

19. Jia, K.; Zhang, C.; Yang, Y.Z.; You, Z. Delimitation of Urban Growth Boundary Based on the Coordination of Ecology and Residential Activity Spaces: A Case Study of Jinan, China. J. Resour. Ecol. 2019, 10, 518-524.

20. Wang, Y.D.; Gu, Y.Y.; Dou, M.X.; Qiao, M.L. Using Spatial Semantics and Interactions to Identify Urban Functional Regions. ISPRS Int. Geo Inf. 2018, 7, 130. [CrossRef]

21. He, L.; Yang, B.X.; Zhang, Y.; Peng, W.F. Structural Analysis of Land Use in Nanchong Gaoping District. J. Mianyang Teach. Coll. 2019, 38, 115-121.

22. Xiang, X.L.; Chen, Y.P. Quantitative analysis of land use structure under township scale of Wumen Mountainous Area in Guizhou. Guizhou Sci. 2019, 37, 47-54.

23. Su, G.S. Quantitative Structure Analysis of Karst Land Use Based on Gibbs-Mirtin Diversification Index: A Case Study of Du'an in Guangxi. J. Guangxi Inst. Educ. 2009, 103, 157-160.

24. Gu, C.L.; Yu, T.F.; Li, W.M. Pattern, Process and Mechanism of Urbanization in China; Science Press: Beijing, China, 2008.

25. Zhang, Z.B. The strategic significance and reform problems of new urbanization. J. Chin. Acad. Gov. 2013, $15,48-54$.

26. He, J.F.; Zhuang, D.F. Analysis of the relationship between urban dynamic change pattern of the Yangtze River Delta and the regional eco-environment. Geograph. Res. 2006, 25, 388-396.

27. Li, W.L.; Zhang, L.J.; Chen, H.; Zhang, J.F.; Gao, Y.H. Study on the Relationship between Urban Expansion and Land Surface Thermal Environment Change in Harbin City. Areal Res. Dev. 2010, 29, 49-53.

28. Wan, Y.; Chen, Y.H.; Li, J. Urban Spatial Pattern and Dynamic Expansion in Henan Province Based on DMSP/OLS Data. Geograph. Geo Inf. Sci. 2019, 35, 89-94.

29. Wuhan Land and Resources Bureau and Planning Bureau. The 13th Five-Year Plan of Land Use and Spatial Distribution in Wuhan; Wuhan Land and Resources Bureau and Planning Bureau: Wuhan, China, 2017. 
30. Xiao, L. The Research on Urban Block; Tongji University: Shanghai, China, 2006.

31. Wang, Y.B.; Zhang, L.Q.; Mathiopoulos, P.T.; Deng, H. A Gestalt rules and graph-cut-based simplification framework for urban building models. Int. J. Appl. Earth Obs. Geoinf. 2015, 35, 247-258. [CrossRef]

32. Hu, H.; Zhao, G.Y.; Wang, H.J. Analysis of Structure Marine Area Use Based on Gibbs-Mirtin Diversification Index. Nat. Resour. Econ. China 2017, 360, 52-55.

33. Wang, S.; Li, J. Analysis and Visualization of POI Distribution Density Based on Urban Network Space. Urban Geotech. Investig. Surv. 2015, 01, 21-25.

34. Mao, Z.Y.; Li, L. The Measure of Spatial Pattern and its Application; Science Press: Beijing, China, 2004.

35. Xie, Z.X.; Yan, J. Kernel density estimation of traffic accidents in a network space. Comput. Environ. Urban Syst. 2008, 32, 396-406. [CrossRef]

36. Yu, W.H.; Ai, T.H. The visualization and analysis of urban facility POIs using network kernel density estimation constrained by multi-factors. Bol. De Cienc. Geod. 2014, 20, 902-926. [CrossRef]

37. Wuhan Municipal People's Government. Statistical Yearbook; Wuhan Municipal People's Government: Wuhan, China, 2017.

38. Chi, J.; Jiao, L.M.; Dong, T.; Gu, Y.Y.; Ma, Y.L. Quantitative Identification and Visualization of Urban Functional Area Based on POI Data. J. Geomat. 2018, 41, 68-73.

39. Classifying Numerical Fields for Graduated Symbology. The Help File of ArcMap 10.2. Available online: http://desktop.arcgis.com/en/arcmap/10.3/map/working-with-layers/classifying-numerical-fields-forgraduated-symbols.htm (accessed on 19 November 2019).

40. Wang, J.H.; Deng, Y.; Song, C.; Tian, D.J. Measuring time accessibility and its spatial characteristics in the urban areas of Beijing. J. Geogr. Sci. 2016, 26, 1754-1768. [CrossRef]

41. Wang, L.; Shen, J.; Chung, C.K.L. City profile: Suzhou-a Chinese city under transformation. Cities 2015, 44, 60-72. [CrossRef]

42. Jendryke, M.; McClure, S.C.; Balz, T.; Liao, M.S. Monitoring the built-up environment of Shanghai on the street-block level using SAR and volunteered geographic information. Int. J. Digit. Earth 2017, 10, 675-686. [CrossRef]

43. Yao, Y.; Hong, Y.; Wu, D.Q.; Zhang, Y.T.; Guan, Q.F. Estimating the effects of "community opening" policy on alleviating traffic congestion in large Chinese cities by integrating ant colony optimization and complex network analyses. Comput. Environ. Urban Syst. 2018, 70, 163-174. [CrossRef]

44. Luo, H.M.; Zhang, Y.M. Study of the experience of new town planning, construction, and management in Singapore and the experience for Nanjing. In Proceedings of the 2011 International Conference on Remote Sensing, Environment and Transportation Engineering, Nanjing, China, 24-26 June 2011; pp. 1618-1620.

45. Ryan, B.D.; Larson, S. Building like Moses with Jacobs in Mind: Contemporary Planning in New York City. Int. J. Urban Reg. Res. 2012, 39, 172-174. [CrossRef]

46. Lytras, M.D.; Visvizi, A.; Sarirete, A. Clustering Smart City Services: Perceptions, Expectations, Responses. Sustainability 2019, 11, 1669. [CrossRef]

(C) 2019 by the authors. Licensee MDPI, Basel, Switzerland. This article is an open access article distributed under the terms and conditions of the Creative Commons Attribution (CC BY) license (http://creativecommons.org/licenses/by/4.0/). 